Review

\title{
Effects and moderators of coping skills training on symptoms of depression and anxiety in patients with cancer: Aggregate data and individual patient data meta-analyses
}

L.M. Buffart ${ }^{\mathrm{a}, \mathrm{b}, *}$, M.A.C. Schreurs ${ }^{\mathrm{c}}$, H.J.G. Abrahams ${ }^{\mathrm{d}}$, J. Kalter ${ }^{\mathrm{e}}$, N.K. Aaronson ${ }^{\mathrm{f}}$, P.B. Jacobsen ${ }^{\mathrm{g}}$, R.U. Newton ${ }^{\mathrm{b}}$, K.S. Courneya ${ }^{\mathrm{h}}$, J. Armes ${ }^{\mathrm{i}}$, C. Arving ${ }^{\mathrm{j}}$, A.M. Braamse ${ }^{\mathrm{d}}$, Y. Brandberg ${ }^{\mathrm{k}}$, J. Dekker $^{1, \mathrm{~m}}$, R.J. Ferguson ${ }^{n}$, M.F. Gielissen ${ }^{\circ}$, B. Glimelius ${ }^{\mathrm{p}}$, M.M. Goedendorp ${ }^{\mathrm{q}, \mathrm{r}}$, K.D. Graves ${ }^{\mathrm{s}}$, S.P. Heiney ${ }^{\mathrm{t}}$, R. Horne ${ }^{\mathrm{u}}$, M.S. Hunter ${ }^{\mathrm{v}}$, B. Johansson ${ }^{\mathrm{p}}$, L.L. Northouse $^{\mathrm{w}}$, H.S. Oldenburg ${ }^{\mathrm{x}}$, J.B. Prins ${ }^{\mathrm{y}}$, J. Savard ${ }^{\mathrm{z}}$, M. van Beurden ${ }^{\text {aa }}$, S.W. van den Berg ${ }^{\mathrm{y}}$, J. Brug $^{\mathrm{ab}}$, H. Knoop ${ }^{\mathrm{d}}$, I.M. Verdonck-de Leeuw ${ }^{\text {ac,ad }}$

${ }^{a}$ Department of Physiology, Radboud University Medical Center, Radboud Institute for Health Sciences, Nijmegen, the Netherlands

${ }^{\mathrm{b}}$ Exercise Medicine Research Institute, Edith Cowan University, Joondalup, WA, Australia

${ }^{\mathrm{c}}$ Department of Medical Oncology, Family Cancer Clinic, Erasmus MC Cancer Institute, Rotterdam, the Netherlands

${ }^{\mathrm{d}}$ Department of Medical Psychology, Amsterdam Public Health research institute, Amsterdam UMC, University of Amsterdam, Amsterdam, The Netherlands

${ }^{\mathrm{e}}$ Division of Human Nutrition and Health, Wageningen University and Research, Wageningen, The Netherlands

${ }^{\mathrm{f}}$ Division of Psychosocial Research and Epidemiology, Netherlands Cancer Institute, Amsterdam, the Netherlands

${ }^{\mathrm{g}}$ Division of Cancer Control and Population Science, National Cancer Institute, Bethesda, MD, Florida, USA

${ }^{\mathrm{h}}$ Faculty of Kinesiology, Sport, and Recreation, University of Alberta, Edmonton, Alberta, Canada

${ }^{i}$ School of Health Science, University of Surrey, Surrey, UK

${ }^{\mathrm{j}}$ Department of Public Health and Caring Sciences, Uppsala University, Uppsala, Sweden

${ }^{\mathrm{k}}$ Department of Oncology-Pathology, Karolinska Institutet, Stockholm, Sweden

${ }^{1}$ Department of Rehabilitation Medicine, Amsterdam UMC, Vrije Universiteit Amsterdam, Amsterdam, the Netherlands

${ }^{m}$ Department of Psychiatry, Amsterdam UMC, Vrije Universiteit Amsterdam, Amsterdam, the Netherlands

${ }^{\mathrm{n}}$ Division of Hematology-Oncology, University of Pittsburgh Cancer Institute, Pittsburgh, PA, USA

${ }^{\circ}$ Academy Het Dorp/Siza, Arnhem, the Netherlands

${ }^{\mathrm{p}}$ Department of Immunology, Genetics and Pathology, Uppsala University, Uppsala, Sweden

${ }^{\mathrm{q}}$ Department of Health Science, Faculty of Sciences, Vrije Universiteit Amsterdam, Amsterdam Public Health Research Institute, Amsterdam, the Netherlands

${ }^{\mathrm{r}}$ Department of Health Psychology, University Medical Center Groningen, University of Groningen, Groningen, the Netherlands

${ }^{\mathrm{s}}$ Lombardi Comprehensive Cancer Center, Georgetown University, Washington, DC, USA

${ }^{\mathrm{t}}$ College of Nursing, University of South Carolina, Columbia, SC, USA

${ }^{\mathrm{u}}$ UCL School of Pharmacy, University College London, London, UK

${ }^{\mathrm{v}}$ Institute of Psychiatry, Psychology and Neuroscience, King's College London, London, UK

${ }^{\mathrm{w}}$ University of Michigan School of Nursing, Ann Arbor, MI, USA

${ }^{\mathrm{x}}$ Department of Surgical Oncology, Netherlands Cancer Institute/Antoni van Leeuwenhoek Hospital, Amsterdam, the Netherlands

${ }^{y}$ Department of Medical Psychology, Radboud University Medical Center, Radboud Institute of Health Sciences, Nijmegen, the Netherlands

${ }^{\mathrm{z}}$ School of Psychology, Université Laval and Laval University Cancer Research Center, Québec, QC, Canada

${ }^{\text {aa }}$ Department of Gynecology, Netherlands Cancer Institute/Antoni van Leeuwenhoek Hospital, Amsterdam, the Netherlands

\footnotetext{
*Corresponding author at: Radboudumc, Department of Physiology, Philips van Leydenlaan 15, 6525 EX Nijmegen, the Netherlands.

E-mail addresses: laurien.buffart@radboudumc.nl (L.M. Buffart), m.a.c.schreurs@erasmusmc.nl (M.A.C. Schreurs),

harriet_abrahams@hotmail.com (H.J.G. Abrahams), joeri.kalter@wur.nl (J. Kalter), n.aaronson@nki.nl (N.K. Aaronson), jacobsen.phd@gmail.com (P.B. Jacobsen), r.newton@ecu.edu.au (R.U. Newton), kerry.courneya@ualberta.ca (K.S. Courneya), jo.armes@surrey.ac.uk (J. Armes), cecilia.arving@pubcare.uu.se (C. Arving), a.m.braamse@amsterdamumc.nl (A.M. Braamse), yvonne.brandberg@ki.se (Y. Brandberg), J.Dekker@amsterdamumc.nl (J. Dekker), fergusonrj2@upmc.edu (R.J. Ferguson), marieke.gielissen@siza.nl (M.F. Gielissen), bengt.glimelius@igp.uu.se (B. Glimelius), m.m.goedendorp@vu.nl (M.M. Goedendorp), kristi.graves@georgetown.edu (K.D. Graves), heineys@mailbox.sc.edu (S.P. Heiney), rob.horne@pharmacy.ac.uk (R. Horne), myra.hunter@kcl.ac.uk (M.S. Hunter), birgitta.johansson@igp.uu.se (B. Johansson), lnortho@umich.edu (L.L. Northouse), h.oldenburg@nki.nl (H.S. Oldenburg), judith.prins@radboudumc.nl (J.B. Prins), Josee.Savard@psy.ulaval.ca (J. Savard), m.v.beurden@nki.nl (M. van Beurden), sw_vandenberg@yahoo.com (S.W. van den Berg), Johannes.brug@rivm.nl (J. Brug), hans.knoop@amsterdamumc.nl (H. Knoop), im.verdonck@amsterdamumc.nl (I.M. Verdonck-de Leeuw).
}

https://doi.org/10.1016/j.cpr.2020.101882 
${ }^{\mathrm{ab}}$ National Institute of Public Health and the Environment, Bilthoven, the Netherlands

${ }^{\text {ac }}$ Department of Otolaryngology-Head and Neck Surgery and Cancer Center Amsterdam, Amsterdam UMC, Vrije Universiteit Amsterdam, the Netherlands

${ }^{\text {ad }}$ Vrije Universiteit Amsterdam, Department of Clinical, Neuro- and Developmental Psychology, Amsterdam Public Health Research Institute, the Netherlands

\section{H I G H L I G H T S}

- The average effect of CST on symptoms of anxiety and depression in cancer patients are statistically significant but small

- Younger patients and patients who received chemotherapy benefit more from CST

- CST effects are larger when delivered face-to-face, led by a psychologist and targeted to patients with psychological distress

\section{A R T I C L E I N F O}

\section{Keywords:}

Psychosocial care

Coping skills training

Neoplasm

Anxiety

Depression

(individual patient data) meta-analysis

\begin{abstract}
A B S T R A C T
Purpose: This study evaluated the effects of coping skills training (CST) on symptoms of depression and anxiety in cancer patients, and investigated moderators of the effects.

Methods: Overall effects and intervention-related moderators were studied in meta-analyses of pooled aggregate data from 38 randomized controlled trials (RCTs). Patient-related moderators were examined using linear mixedeffect models with interaction tests on pooled individual patient data $(n=1953)$ from 15 of the RCTs.

Results: CST had a statistically significant but small effect on depression ( $\mathrm{g}=-0.31,95 \%$ confidence interval $(\mathrm{CI})=-0.40 ;-0.22)$ and anxiety $(\mathrm{g}=-0.32,95 \% \mathrm{CI}=-0.41 ;-0.24)$ symptoms. Effects on depression symptoms were significantly larger for interventions delivered face-to-face $(p=.003)$, led by a psychologist $(p=.02)$ and targeted to patients with psychological distress $(p=.002)$. Significantly larger reductions in anxiety symptoms were found in younger patients ( $\mathrm{p}_{\text {interaction }}<0.025$ ), with the largest reductions in patients $<50$ years $(\beta=-0.31,95 \% \mathrm{CI}=-0.44 ;-0.18)$ and no significant effects in patients $\geq 70$ years. Effects of CST on depression $(\beta=-0.16,95 \% \mathrm{CI}=-0.25 ;-0.07)$ and anxiety $(\beta=-0.24,95 \% \mathrm{CI}=-0.33 ;-0.14)$ symptoms were significant in patients who received chemotherapy but not in patients who did not ( $\mathrm{p}_{\text {interaction }}<0.05$ ).

Conclusions: CST significantly reduced symptoms of depression and anxiety in cancer patients, and particularly when delivered face-to-face, provided by a psychologist, targeted to patients with psychological distress, and given to patients who were younger and received chemotherapy.
\end{abstract}

\section{Introduction}

A substantial proportion of patients with cancer experience symptoms of depression and anxiety (these symptoms will be referred to as depression and anxiety throughout the manuscript for clarity). Previous studies found that $7-31 \%$ of patients suffer from depression and $8-19 \%$ of patients experience anxiety, with proportions varying by the type of cancer and assessment method (Krebber et al., 2014; Mitchell et al., 2011; Zhu et al., 2017). Evidence suggests that, next to fatigue (Barsevick et al., 2013) and pain (van den Beuken-van Everdingen, Hochstenback, Joosten, Tjan-Heijnen, \& Janssen, 2016), depression and anxiety are among the most common symptoms that affect cancer patients' health-related quality of life (Cleeland et al., 2000; Dauchy, Dolbeault, \& Reich, 2013; Hutter et al., 2013; Jacobsen \& Jim, 2008; Nikbakhsh, Moudi, Abbasian, \& Khafri, 2014; Pirl, 2004) and treatment adherence (Arrieta et al., 2013; Barber et al., 2015). It is therefore important to adequately address depression and anxiety in clinical cancer care.

Various psychosocial interventions are available to manage depression and anxiety, which can be subdivided into psycho-education, supportive interventions with a focus on acknowledgement of problems and expression of emotions, coping skills training (CST), (psycho-dynamic) psychotherapy and spiritual or existential therapy (Cunningham A.J. 1995). Although each of these types of interventions can be used to treat or ameliorate depression and anxiety in cancer patients, the focus here will be on the evidence on the efficacy of CST, as this is the most prevalent form of therapy (Kalter et al., 2018). CST, which encompasses interventions like cognitive behavioural therapy (CBT) or problem solving therapy, aims to enhance the patient's ability to cope with the sequela of cancer and its treatment. In these interventions, patients learn new cognitive-behavioural skills such as relaxation, mental imagery, thought and affect management, and activity planning (Jacobsen \& Jim, 2008; Kalter et al., 2018). Results from previous meta-analyses have shown that CST reduces depression (medium effect size of
$0.34-0.38$ ) and anxiety (medium effect size of 0.31-0.42) in patients with cancer (Ballesio et al., 2017; Matthews, Grunfeld, \& Turner, 2016; Sheard \& Maguire, 1999). However, there is a substantial heterogeneity in effects across the different studies that may be explained by specific patient- and intervention-related characteristics. Previous meta-analyses and randomized controlled trials (RCTs) reported larger benefits of CST in men versus women, married versus single patients, patients with breast cancer versus other types of cancer, patients with metastatic versus local or loco-regional disease, patients who received chemotherapy versus other types of treatment, interventions led by a mental health professional versus nurses or other health care professionals, and in studies that specifically selected patients with higher distress levels (Andersson \& Cuijpers, 2009; Faller et al., 2013; Spek et al., 2007; van der Meulen et al., 2015; Willems, Mesters, Lechner, Kanera, \& Bolman, 2017; Williams \& Dale, 2006). Information on these moderators of intervention effects is essential to better target specific patient groups to maximize benefits of CST.

Meta-analyses in which aggregate (summary) data (AD) from a large number of studies are pooled, allow investigations of differences in effects across characteristics of the intervention (Lyman \& Kuderer, 2005). However, AD meta-analyses do not allow testing interactions between the intervention and potential moderator variables at the individual patient level. Rather, AD meta-analyses use measures of central tendency (e.g., means such as with age, or proportions such as with sex) (Riley, Lambert, \& Abo-Zaid, 2010). As a consequence, moderator effects of patient characteristics evaluated in AD meta-analyses may be confounded by other trial characteristics, also referred to as ecological bias (Berlin, Santanna, Schmid, Szczech, \& Feldman, 2002; Riley et al., 2010), and should therefore be interpreted with caution.

Ecological bias can be reduced by using individual patient data (IPD) in a meta-analysis (Berlin et al., 2002; Stewart \& Tierney, 2002; Tierney et al., 2015). However, the collection of IPD is labour intensive and time consuming and depends on the ability and willingness of investigators of eligible studies to share their data. This makes it difficult 
to include all available RCTs, which may introduce retrieval bias in estimating the overall intervention effects (Riley et al., 2010).

In previous analyses on IPD collected in the Predicting OptimaL Cancer RehabIlitation and Supportive care (POLARIS) study (Buffart et al., 2013), we found small but statistically significant effects of psychosocial interventions (including CST) on quality of life ( $\beta=0.12$, $95 \%$ confidence interval $(\mathrm{CI})=0.07 ; 0.17)$, emotional function $(\beta=0.12,95 \% \mathrm{CI}=0.07 ; 0.18)$ and social function $(\beta=0.10$, $95 \% \mathrm{CI}=0.05 ; 0.15$ ) (Kalter et al., 2018). Additionally, moderator effects on one or more of these outcomes were found for age, marital status, treatment with chemotherapy, baseline emotional function, type of psychosocial intervention, and interventions targeting patients with distress (Kalter et al., 2018).

In the present paper, we combine $\mathrm{AD}$ and IPD meta-analyses to reduce retrieval and ecological bias, in the investigations of the effects of CST on depression and anxiety in patients with cancer, and to identify patient-related moderators (i.e., demographic, clinical, and psychosocial characteristics) and intervention-related moderators of those effects.

\section{Methods}

The conduct and reporting of the $\mathrm{AD}$ and IPD meta-analyses are based on the Preferred reporting Items for Systematic Review and MetaAnalyses (PRISMA) (Moher, Liberati, Tetzlaff, \& Altman, 2009) and PRISMA-IPD statement (Stewart \& Tierney, 2002). The IPD were collected as part of the POLARIS study. The study protocol was registered in PROSPERO International prospective register of systematic reviews, in February 2013 (CRD42013003805) (Buffart et al., 2013).

\subsection{Identification and inclusion of studies}

A literature search was conducted in April 2019 to identify studies that could be used to examine the overall effect of CST on depression and anxiety, and the potential moderator effects of intervention-level characteristics via $\mathrm{AD}$ meta-analyses. In contrast to the original broader literature search for POLARIS conducted in 2012 (Kalter et al., 2018), the current literature search specifically focussed on CST and on depression and anxiety as outcomes. Relevant published studies were identified via systematic searches in five electronic databases (PubMed, EMBASE, PsycINFO, CINAHL and CENTRAL), and reference checking of systematic reviews and meta-analyses. Search terms included depression, anxiety, cancer, and psychosocial interventions. The full search terms can be found in Appendix 1. Articles were included when the study 1) was a RCT; 2) included a usual care, wait-list or attention control group; 3 ) included adult patients with cancer (excluding survivors of childhood cancer); 4) measured depression and/or anxiety as one of the outcomes using a validated multi-item questionnaire; and 5) evaluated the effects of coping skills training, as defined by Cunningham (Cunningham A.J. 1995), the goal being to help patients acquire new coping skills. Studies focussing on psychoeducation, support, psychodynamic psychotherapy, and spiritual or existential therapy were excluded from the present analyses (Cunningham A.J. 1995; Kalter et al., 2018).

To investigate demographic, clinical and personal (patient-level) moderators of the effect of CST, we used IPD from the POLARIS study of which detailed descriptions of the design and procedures have been published previously (Buffart et al., 2013; Buffart et al., 2017; Kalter et al., 2018; Kalter, Sweegers, Verdonck-de Leeuw, Brug, \& Buffart, 2019). Briefly, IPD from 22 of 61 eligible RCTs focussing on psychosocial interventions were included in the POLARIS database (Kalter et al., 2018), of which 14 RCTs evaluated the effects of CST on
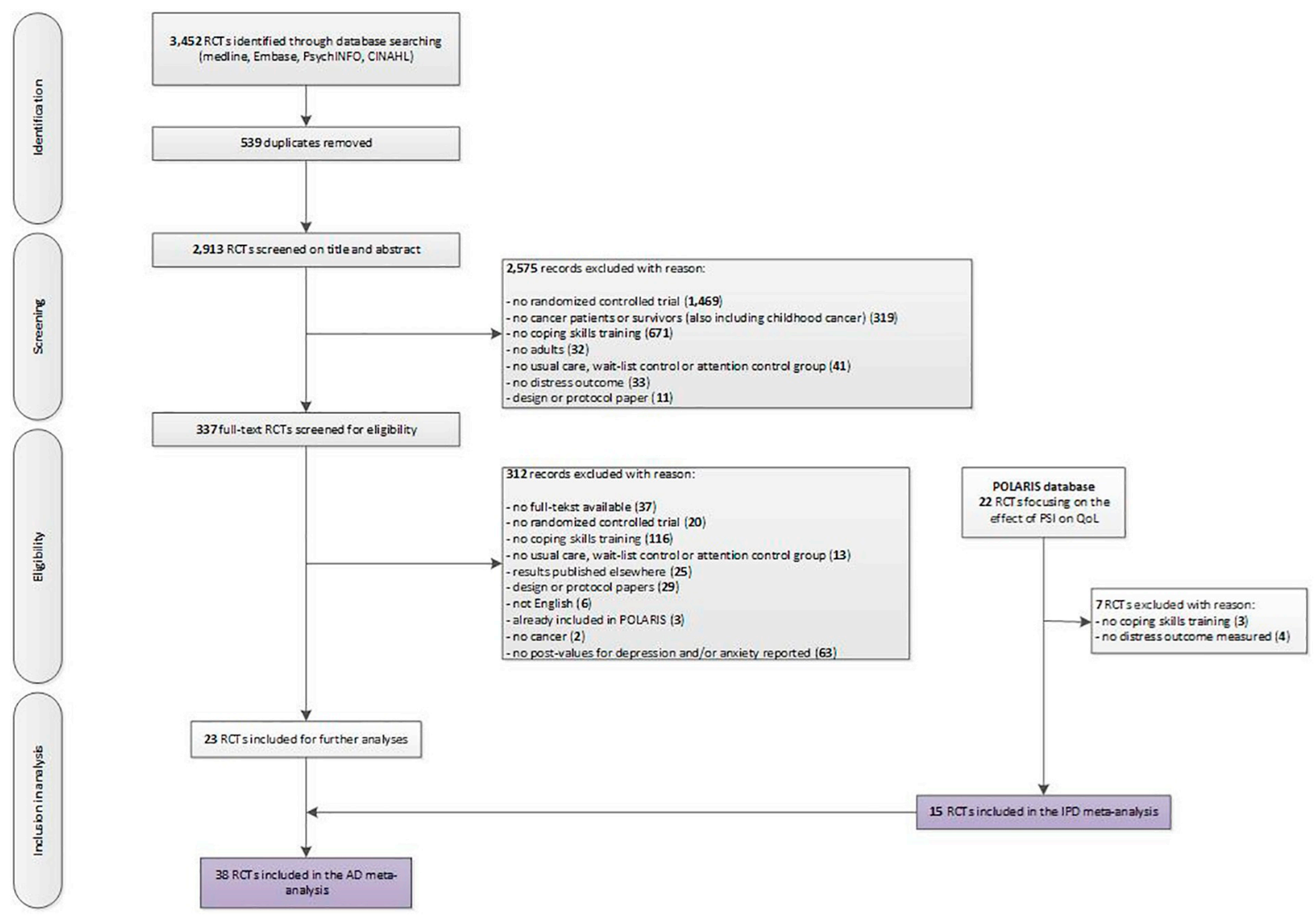

Fig. 1. Flowchart of inclusion randomized controlled trials (RCTs) in the POLARIS study and additionally identified RCTs in the more recent literature search 
depression and anxiety (Armes, Chalder, Addington-Hall, Richardson, \& Hotopf, 2007; Arving et al., 2007; Braamse et al., 2016; Duijts, Oldenburg, van Beurden, \& Aaronson, 2012; Ferguson et al., 2012; Gellaitry, Peters, Bloomfield, \& Horne, 2010; Gielissen, Verhagen, Witjes, \& Bleijenberg, 2006; Goedendorp et al., 2010; Graves, Carter, Anderson, \& Winett, 2003; Heiney et al., 2003; Johansson et al., 2008; Mann et al., 2012; Savard, Simard, Ivers, \& Morin, 2005; van den Berg, Gielissen, Custers, van der Graaf, \& Ottevanger, 2015), and one additional RCT assessed the effects on depression only (Northouse et al., 2013). Detailed information on the selection of studies can be found in the flowchart (Fig. 1). Detailed information on reasons for not sharing IPD is presented in our previous publication (Kalter et al., 2018).

\subsection{Outcome variables}

Depression and anxiety were assessed with validated, multi-item patient-reported outcome measures (PROMs). We used baseline or preintervention and the first post-intervention assessments to evaluate the short-term intervention effects of CST on depression and anxiety. As some studies used multiple questionnaires to assess depression and/or anxiety, we selected the most-frequently used symptom-specific questionnaires over generic questionnaires or other symptom-specific questionnaires for analyses. The Center for Epidemiologic Studies Depression Scale (CES-D) was chosen over the Profile of Mood States (POMS) depression subscale in one study (Ferguson et al., 2012), and in three studies the depression subscale of the Hospital Anxiety and Depression Scale (HADS-D) was used instead of the Patient Health Questionnaire (Braamse et al., 2016), the Symptom Checklist (van den Berg et al., 2015) and the Beck Depression Inventory (Savard et al., 2005). For anxiety, the State-Trait Anxiety Inventory (STAI) was chosen over the Symptom Checklist (Goedendorp et al., 2010) and the POMS anxiety subscale (Ferguson et al., 2012) in two studies and the HADS-A over the Symptom Checklist (van den Berg et al., 2015). In one study (Braamse et al., 2016), both HADS-A and STAI were included, and the data from the HADS-A was selected as this was the most frequently used PROM.

\subsection{Possible moderators}

Potential intervention-related moderators (to be used in the AD meta-analyses) were identified from previously conducted meta-analyses (Andersson \& Cuijpers, 2009; Faller et al., 2013; Kalter et al., 2018; Schneider et al., 2010; Spek et al., 2007). They included timing and method of intervention delivery, intervention strategy, intervention duration, intervention focus, health-care professional leading the intervention and whether the intervention targeted patients with elevated levels of depression or anxiety. The timing of intervention delivery was categorized as during treatment or after cancer treatment according to the Physical Activity and Cancer Control framework (Courneya \& Friedenreich, 2007). The method of delivery was dichotomised into face-to-face intervention or other (telephone/web-/video-based). As cognitive behavioural therapy was the most frequently used CST, we dichotomised intervention strategy into cognitive behavioural therapy versus other (e.g., problem solving therapy, stress management training, expressive writing). Intervention duration was dichotomised into $\leq 12$ weeks versus $>12$ weeks. Intervention focus was dichotomised into psychological distress (anxiety/depression) versus other outcomes (e.g., fatigue, insomnia, quality of life). The health care professional leading the intervention was categorized as psychologist, nurse, or other. Further, studies were dichotomised into those that specifically targeted patients with high levels of depression and/or anxiety before the start of the intervention and those that did not.

Potential demographic, clinical and personal moderators that we studied in the IPD meta-analyses were identified from previous publications on the moderator effects of CST or other psychosocial interventions (Badger et al., 2013; Faller et al., 2013; Guo et al., 2013;
Heron-Speirs, Baken, \& Harvey, 2012; Heron-Speirs, Harvey, \& Baken, 2013). Potential demographic moderators included baseline age, sex, marital status, education level, and baseline values of depression or anxiety, and were categorized in line with our previous publications (Buffart et al., 2017; Kalter et al., 2018). We dichotomised marital status into single versus married or living with partner, and education level into low-medium (elementary, primary, or secondary school, lower or secondary vocational education) or high (higher vocational, college, or university education). Baseline values for depression and anxiety were assessed as moderators by using the pooled z-score. Potential clinical moderators included type of cancer, the presence of distant metastases at baseline, and type of cancer treatment. Type of cancer was categorized into breast, male genitourinary, gastrointestinal, hematological, gynecological, respiratory tract, and other types. The presence of distant metastasis and type of treatment (i.e. surgery, chemotherapy, radiotherapy, SCT and hormone therapy) were dichotomized. As hormone therapy for breast cancer may continue for several years after treatment, women on hormone therapy only (who completed other primary cancer treatments) were considered as being after treatment.(Kalter et al., 2018) Men receiving androgen deprivation therapy for prostate cancer were considered as being during treatment.(Kalter et al., 2018).

\subsection{Quality assessment}

Two independent researchers rated the quality of the included studies from published papers using the Cochrane 'risk of bias' assessment tool (J. P. Higgins et al., 2011). The quality rating of the studies with IPD has been described previously (Kalter et al., 2018). The quality was graded as high $(+)$, low $(-)$ or unclear (?) on the following aspects: random sequence generation (high quality if a random assignment was used), allocation concealment (high quality in case of central, computerized allocation or use of sequentially numbered sealed envelopes), incomplete outcome (high quality if intention-to-treat analyses were performed, and less than $10 \%$ of the outcome data were missing or adequate imputation techniques were used), and incomplete reporting (high quality if the outcome was reported such that the data could be entered in the $\mathrm{AD}$ meta-analysis). Other potential sources of bias that were rated were adherence (high quality if $\geq 80 \%$ of intervention sessions were attended) and contamination (high quality in case of no or limited adoption $(<20 \%)$ of the intervention in the control group). Items related to blinding were omitted because blinding of patients and personnel is difficult in case of CST. Also, the rating of blinding of outcome assessors was excluded because anxiety and distress were assessed with PROMs.

\subsection{Statistical analysis}

Descriptive statistics (mean, standard deviation (SD), numbers and proportions) were used to describe the patient-, and intervention-related characteristics.

\subsubsection{Aggregate data $(A D)$ meta-analysis}

Effect sizes for all individual studies included in the AD meta-analyses were calculated by subtracting the published average post-intervention values of symptoms of depression and anxiety of the intervention group from the values of the control group, and dividing the result by the pooled SD of the intervention and control group (Cuijpers, 2016). When average scores or SD were not reported, we investigated whether other statistics could be used to calculate effects sizes (i.e., average scores and 95\% CI, between-group differences and $p$-values). Studies were considered outliers if the $95 \%$ CI of the effect did not overlap with the 95\% CI of the pooled effect (Cuijpers, 2016). We performed all AD meta-analyses with and without outliers. The heterogeneity was high when outlies were included, also in the subgroups

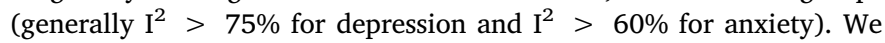


therefore presented the results of $\mathrm{AD}$ meta-analyses without outliers, reducing the heterogeneity. All individual effect sizes were pooled in a random effects model using Hedges g, thereby adjusting for studies with small sample sizes (Hedges \& Olkin, 1985). Using Cohen's convention, effects of $0.2-0.49$ were considered small, $0.50-0.79$ as moderate and at or above 0.8 as large (Cohen, 2013). The $\mathrm{I}^{2}$ statistic was reported as an indicator of heterogeneity, with an $\mathrm{I}^{2}$ of $25 \%$ representing low, $50 \%$ representing moderate and $75 \%$ representing high heterogeneity (Higgins, Thompson, Deeks, \& Altman, 2003).

Analyses of the overall effect and differences in effects between subgroups across intervention-related moderators were conducted using Comprehensive Meta-Analysis software (V.2.2.064). Differences between subgroups were considered statistically significant when $p \leq .05$.

\subsubsection{Individual patient data (IPD) meta-analysis}

To allow pooling of the different PROMs in the IPD meta-analysis, individual scores were recoded into z-scores by subtracting the mean score at baseline from the individual score, then dividing the result by the mean standard deviation per outcome measure at baseline. Subsequently, the pooled z-scores were used for further analyses.

A one-step IPD meta-analysis was conducted to study whether patient-level characteristics moderated the effects of CST on depression and anxiety. Linear mixed model analyses with a two-level structure (1: patient; 2: study) were used to take into account the clustering of patients within studies by using a random intercept on study level. To limit regression to the mean, the post-intervention value (z-scores) of the outcome was regressed onto the intervention and adjusted for the baseline value (z-scores). Moderators of intervention effects were

Table 1

Description of characteristics of the studies included in the individual patient data (IPD) and aggregate data (AD) meta-analyses (38 studies, $n=5246$ ).

\begin{tabular}{|c|c|c|c|c|c|c|c|c|c|c|c|c|c|}
\hline \multirow[t]{2}{*}{ Study (first author, year) } & \multirow[t]{2}{*}{ Country } & \multirow[t]{2}{*}{ Study sample (n) } & \multirow[t]{2}{*}{ Mean Age (yr) } & \multirow{2}{*}{$\begin{array}{l}\text { Sex } \\
\text { (\% male) }\end{array}$} & \multirow[t]{2}{*}{ Type of cancer } & \multirow[t]{2}{*}{ PROM depression } & \multirow{2}{*}{$\begin{array}{l}\text { PROM } \\
\text { anxiety }\end{array}$} & \multicolumn{6}{|c|}{ Quality assessment } \\
\hline & & & & & & & & RSG & AC & IO & IR & Adh & Con \\
\hline \multicolumn{14}{|c|}{ Studies included in IPD meta-analysis only } \\
\hline Armes et al., 2007 & UK & 60 & 59 & 40 & Mixed & HADS-D & HADS-A & + & + & + & + & - & $?$ \\
\hline Arving et al., 2007 & SWE & 179 & 55 & 0 & Breast & HADS-D & HADS-A & + & $?$ & + & + & $?$ & $?$ \\
\hline Braamse et al., 2016 & NL & 95 & 54 & 68 & Hematologic & HADS-D & HADS-A & + & + & + & + & - & + \\
\hline Duijts et al., 2012 & NL & 212 & 48 & 0 & Breast & HADS-D & HADS-A & + & + & + & + & - & $?$ \\
\hline Ferguson et al., 2012 & USA & 40 & 50 & 0 & Breast & CES-D & STAI-S & + & + & + & + & $?$ & $?$ \\
\hline Gellaitry et al., 2010 & UK & 93 & 58 & 0 & Breast & POMS & POMS & + & $?$ & - & - & $?$ & $?$ \\
\hline Gielissen et al., 2006 & NL & 112 & 45 & 51 & Mixed & BDI & STAI-S & $?$ & + & + & + & $?$ & $?$ \\
\hline Goedendorp et al., 2010 & NL & 163 & 56 & 36 & Mixed & POMS & POMS & + & + & + & - & $?$ & $?$ \\
\hline Graves et al., 2003 & USA & 32 & 56 & 0 & Breast & POMS & POMS & $?$ & $?$ & - & - & $?$ & $?$ \\
\hline Heiney et al., 2003 & USA & 66 & 50 & 0 & Breast & POMS & POMS & + & $?$ & - & + & + & $?$ \\
\hline Johansson et al., 2008 & SWE & 260 & 64 & 43 & Mixed & HADS-D & HADS-A & + & + & $?$ & + & $?$ & $?$ \\
\hline Mann et al., 2012 & UK & 96 & 54 & 0 & Breast & WHQ & WHQ & + & + & + & + & + & $?$ \\
\hline Northouse et al., 2013 & USA & 484 & 60 & 39 & Mixed & CES-D & - & + & + & + & + & + & + \\
\hline Savard et al., 2005 & CAN & 57 & 54 & 0 & Breast & HADS-D & HADS-A & + & $?$ & + & + & + & $?$ \\
\hline van den Berg et al., 2015 & NL & 150 & 51 & 0 & Breast & HADS-D & HADS-A & + & + & + & + & + & $?$ \\
\hline \multicolumn{14}{|c|}{ Additional studies identified for $A D$ meta-analysis } \\
\hline Aguado Loi et al., 2012 & USA & 220 & 57 & 20 & Mixed & CES-D & STAI-S & + & + & + & + & 0 & ? \\
\hline Aguado Loi et al., 2017 & USA & 219 & 55 & 29 & Mixed & CES-D & STAI-S & + & + & + & + & 0 & $?$ \\
\hline Badger et al., 2007 & USA & 75 & 54 & 0 & Breast & CES-D & Combination $^{\mathrm{a}}$ & $?$ & $?$ & $?$ & + & + & $?$ \\
\hline Desautels et al., 2018 & CAN & 62 & 57 & 0 & Breast & HADS-D & - & + & + & + & + & $?$ & $?$ \\
\hline Dirksen \& Epstein, 2008 & USA & 81 & 58 & 0 & Breast & CES-D & STAI-S & + & + & $?$ & + & $?$ & $?$ \\
\hline do Carmo et al., 2017 & Brazil & 63 & 53 & 65 & Mixed & HADS-D & HADS-A & + & + & + & + & + & - \\
\hline Downe-Wamboldt et al., 2007 & USA & 175 & 62 & 40 & Mixed & CES-D & - & + & + & - & + & 0 & $?$ \\
\hline Garssen et al., 2013 & NL & 85 & 53 & 0 & Breast & POMS & STAI-S & - & $?$ & + & + & $?$ & $?$ \\
\hline Gonzalez-Fernandez et al., 2018 & Spain & 52 & 52 & 8 & Mixed & HADS-D & HADS-A & $?$ & $?$ & - & + & $?$ & $?$ \\
\hline Kangas et al., 2013 & AUS & 35 & 55 & 80 & Head/neck & BDI & STAI-S & $?$ & $?$ & + & + & $?$ & $?$ \\
\hline Kurtz et al., 2005 & USA & 237 & 55 & 47 & Mixed & CES-D & - & ? & $?$ & - & + & $?$ & $?$ \\
\hline Manne et al., 2017 & USA & 234 & 55 & 0 & Gynecologic & BDI & - & $?$ & $?$ & + & + & $?$ & $?$ \\
\hline Napoles et al., 2015 & USA & 151 & 51 & 0 & Breast & GSD & GSD & + & + & + & + & + & $?$ \\
\hline Ream et al., 2015 & UK & 44 & 53 & 39 & Mixed & HADS-D & HADS-A & + & $?$ & - & + & $?$ & ? \\
\hline Ren et al., 2019 & $\mathrm{CHN}$ & 392 & 47 & 0 & Breast & HAMD & HAMA & + & + & + & + & $?$ & $?$ \\
\hline Steel et al., 2016 & USA & 261 & 61 & 73 & Mixed & CES-D & - & + & + & $?$ & + & 0 & $?$ \\
\hline Stefanopoulou et al., 2015 & UK & 68 & 69 & 100 & Prostate & HADS-D & HADS-A & + & + & + & + & $?$ & $?$ \\
\hline Stoerkel et al., 2018 & USA & 100 & $?$ & 0 & Breast & PROMIS-D & PROMIS-A & + & + & - & + & + & $?$ \\
\hline Strong et al., 2008 & UK & 200 & 57 & 29 & Mixed & SCL-20 & SCL-10 & + & + & + & + & $?$ & $?$ \\
\hline van de Wal et al., 2017 & NL & 88 & 59 & 47 & Mixed & HADS-D & HADS-A & + & + & + & + & - & $?$ \\
\hline Van der Meulen et al., 2012 & NL & 205 & 60 & 70 & Head/neck & CES-D & - & $?$ & + & + & + & - & + \\
\hline Wells-Di Gregorio et al., 2019 & USA & 28 & 57 & 18 & Mixed & - & STAI & + & + & + & + & - & $?$ \\
\hline Wu et al., 2016 & $\mathrm{CHN}$ & 72 & 51 & 25 & Thyroid & SDS & SAS & $?$ & $?$ & - & + & 0 & $?$ \\
\hline
\end{tabular}

Notes. The number of patients was reported at baseline. The number of patients included in the analyses might therefore differ as i.e. not all patients completed the questionnaire.

Abbreviations: AD-MA = Aggregate Data Meta-analysis; AUS = Australia; BDI: Beck Depression Index; CAN=Canada; CES-D: Center for Epidemiologic Studies Depression Scale; CHN =China; DASS21 = Depression, Anxiety and Stress Scale, 21-item version, Anxiety $(-\mathrm{A})$, or Depression $(-\mathrm{D})$ subscale; GSD $=$ General Symptoms of Distress; HADS: Hospital Anxiety and Depression Scale; HAMA = Hamilton anxiety scale; HAMD = Hamilton depression rating scale; IPDMA = Individual Patient Data Meta-analysis; NL = The Netherlands; POMS: Profile of Mood States; PROM = Patient-reported Outcome Measure; PROMIS = PatientReported Outcome Measurement Information System-57, Anxiety ( - A) or Depression ( - D) subscale; SAS: Self-rating Anxiety Scale; SCL: Short Checklist - originally contains 90 questions, but here we also found shorter lists; SDS: Self-rating Depression Scale; STAI: State-Trait Anxiety Index; SWE = Sweden; UK= United Kingdom; USA = United States of America; WHQ: Women's Health Questionnaire.

Quality assessment: $+=$ high quality; $-=$ low quality; $=$ unclear quality; $0=$ not applicable; $\mathrm{RSG}=$ random sequence generation; AC $=$ allocation concealment; $\mathrm{IO}=$ incomplete outcome; IR = incomplete reporting; Adh = adherence; Con = contamination.

${ }^{\text {a }}$ Combination of four items from the Positive and Negative Affect Schedule, one item from the Short Form-12, and three items from the Index of Clinical Stress. 


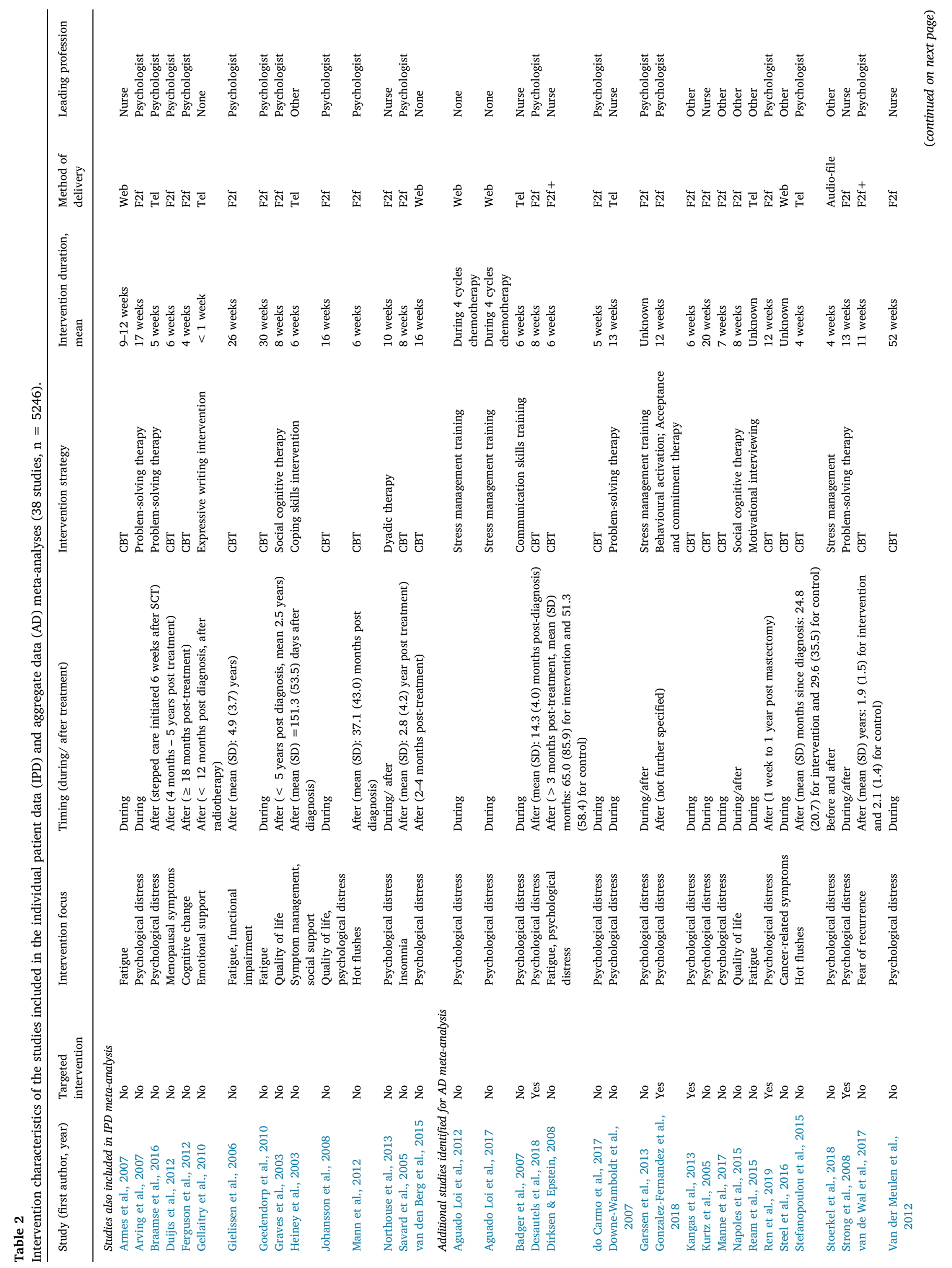


examined by subsequently adding each moderator and its interaction term with the intervention into the regression model. The likelihood ratio test was used to determine whether adding the interaction term significantly improved the fit of the model. To reduce ecological bias for patient-level interactions, within-trial interaction was separated from between-trial interaction by centering the individual value of the covariate around the mean study value of that covariate (Helgeson, Lepore, \& Eton, 2006). Significance level of the interaction terms was set at $p \leq .05$. If adding the interaction term significantly improved the statistical model, strata were built starting with the most significant moderator for both depression and anxiety.

Regression coefficients $(\beta)$ and $95 \%$ CI are reported, which represent the between group difference in z-scores of depression or anxiety, and correspond to a Cohen's d effect size (Cohen, 2013). Statistical analyses were performed using SPSS 22.0 and R Studio.

\subsubsection{Representativeness of the IPD sample and publication bias}

To examine whether the studies included in the IPD meta-analyses were a representative sample of all eligible studies, we compared the pooled effects of RCTs with IPD versus those not included using the published data.

We also investigated publication bias for all eligible studies by inspecting the funnel plot and calculating the effect size with a correction for possible publication bias using Duval and Tweedie's procedure (Duval \& Tweedie, 2000). This procedure trims (removes) studies in case of asymmetry in the funnel plot, estimates the true 'center' of the funnel and replaces (fills) the omitted studies around the center. A statistically significant dispersion between the true effect size and the calculated effect size after correcting for possible missing studies or an asymmetry in the funnel plot, calculated using Egger's test, could suggest publication bias. A $\mathrm{p} \leq .05$ was applied as the criterion for statistical significance.

\section{Results}

\subsection{Characteristics of studies and patients}

The literature search identified 3452 references, of which 23 new RCTs (C. X. Aguado Loi et al., 2017; Claudia X. Aguado Loi et al., 2012; Badger, Segrin, Dorros, Meek, \& Lopez, 2007; Butow et al., 2017; Desautels, Savard, Ivers, Savard, \& Caplette-Gingras, 2018; Dirksen \& Epstein, 2008; do Carmo, Paiva, de Oliveira, Nascimento, \& Paiva, 2017; Downe-Wamboldt et al., 2007; Garssen et al., 2013; GonzalezFernandez, Fernandez-Rodriguez, Paz-Caballero, \& Perez-Alvarez, 2018; Greer et al., 2012; Kangas, Milross, Taylor, \& Bryant, 2013; Kurtz, Kurtz, Given, \& Given, 2005; Manne et al., 2017; Napoles et al., 2015; Ream, Gargaro, Barsevick, \& Richardson, 2015; Ren et al., 2019; Steel et al., 2016; Stefanopoulou, Yousaf, Grunfeld, \& Hunter, 2015; Stoerkel et al., 2018; Strong et al., 2008; van de Wal, Thewes, Gielissen, Speckens, \& Prins, 2017; Van der Meulen et al., 2012; Wells-Di Gregorio et al., 2019; Wu et al., 2016) were added to the 15 RCTs available in the POLARIS database (Fig. 1). This resulted in 37 RCTs evaluating the effects of CST on depression and 31 on anxiety (Table 1). Sample sizes of the included studies ranged from 28 to 484 (Table 1). Of the 38 included RCTs, 17 (45\%) were conducted during cancer treatment, 16 (42\%) after cancer treatment, 4 (11\%) included patients either during or after cancer treatment, and $1(2 \%)$ before and after surgery (Table 2$)$. In total, 25 (66\%) RCTs examined interventions with face-to-face sessions, 21 (55\%) RCTs examined interventions that included CBT as intervention strategy, 26 (68\%) RCTs evaluated interventions with a duration $\leq 12$ weeks, and 17 (45\%) RCTs examined interventions that were led by a psychologist (Table 2). We identified 6 (16\%) RCTs that selected patients based on high levels of distress.

In total, $28(74 \%)$ of the included RCTs reported random sequence generation, 25 (66\%) RCTs reported adequate allocation concealment, $25(66 \%)$ had adequate completeness of outcome data, 35 (92\%) had 
Table 3

Demographic and clinical characteristics, and baseline depression and anxiety of patients included in the individual patient (IPD) meta-analysis.

\begin{tabular}{|c|c|c|}
\hline Variable & $\begin{array}{l}\text { Control } \\
(n=878)\end{array}$ & $\begin{array}{l}\text { Intervention } \\
(n=1075)\end{array}$ \\
\hline \multicolumn{3}{|l|}{ Demographic } \\
\hline Age, mean (SD) years & $54.7(11.2)$ & $55.8(11.3)$ \\
\hline \multicolumn{3}{|l|}{ Age categories, n (\%) } \\
\hline$<50$ years & $291(33.1)$ & $312(29.0)$ \\
\hline $50-70$ years & $493(56.2)$ & $615(57.2)$ \\
\hline$\geq 70$ years & $92(10.5)$ & 147 (13.7) \\
\hline Unknown & $2(0.2)$ & $1(0.1)$ \\
\hline \multicolumn{3}{|l|}{ Gender, n (\%) } \\
\hline Male & $188(21.4)$ & $232(21.6)$ \\
\hline Female & $690(78.4)$ & $843(78.4)$ \\
\hline \multicolumn{3}{|l|}{ Marital status, n (\%) } \\
\hline Single/living alone & $192(21.9)$ & $226(21.0)$ \\
\hline Married/living together & $581(66.2)$ & $747(69.5)$ \\
\hline Unknown & $105(12.0)$ & $102(9.5)$ \\
\hline \multicolumn{3}{|l|}{ Educational level, n (\%) } \\
\hline Low/medium & $384(43.7)$ & $429(39.9)$ \\
\hline High & $230(26.2)$ & $310(28.8)$ \\
\hline Unknown & $264(30.1)$ & $336(31.3)$ \\
\hline \multicolumn{3}{|l|}{ Clinical } \\
\hline \multicolumn{3}{|l|}{ Type of cancer, n (\%) } \\
\hline Breast & $595(67.8)$ & $705(65.6)$ \\
\hline Genitourinary & $93(10.6)$ & $113(10.5)$ \\
\hline Gynecological & $12(1.4)$ & $10(0.9)$ \\
\hline Gastrointestinal & $63(7.2)$ & $108(10.0)$ \\
\hline Lung & $51(5.8)$ & $96(8.9)$ \\
\hline Hematological & $56(6.4)$ & $37(3.4)$ \\
\hline Other & $8(0.9)$ & $6(0.6)$ \\
\hline \multicolumn{3}{|c|}{$\begin{array}{l}\text { Distant metastasis at baseline, } \mathrm{n} \\
(\%)^{\mathrm{a}}\end{array}$} \\
\hline No & $763(86.9)$ & $947(88.1)$ \\
\hline Yes & $50(5.7)$ & $66(6.1)$ \\
\hline Unknown & $65(7.4)$ & $62(5.8)$ \\
\hline \multicolumn{3}{|l|}{ Surgery, n (\%) ${ }^{\mathrm{b}}$} \\
\hline No & $120(13.7)$ & $184(17.1)$ \\
\hline Yes & $708(80.6)$ & $866(80.6)$ \\
\hline Unknown & $50(5.7)$ & $25(2.3)$ \\
\hline \multicolumn{3}{|l|}{ Chemotherapy, n (\%) } \\
\hline No & $273(31.1)$ & $350(32.6)$ \\
\hline Yes & $603(68.7)$ & $722(67.2)$ \\
\hline Unknown & $2(0.2)$ & $3(0.3)$ \\
\hline \multicolumn{3}{|l|}{ Radiotherapy, n (\%) } \\
\hline No & $356(40.5)$ & $480(44.7)$ \\
\hline Yes & $499(56.9)$ & $573(53.3)$ \\
\hline Unknown & $23(2.6)$ & $22(2.0)$ \\
\hline \multicolumn{3}{|l|}{ Hormone therapy } \\
\hline \multicolumn{3}{|l|}{$\begin{array}{l}\text { Patients with breast cancer } \\
(n=1300), \mathrm{n}(\%)\end{array}$} \\
\hline No & $215(36.1)$ & $314(44.5)$ \\
\hline Yes & $327(55.0)$ & $341(48.4)$ \\
\hline Unknown & $53(8.9)$ & $50(7.1)$ \\
\hline \multicolumn{3}{|c|}{$\begin{array}{l}\text { Patients with prostate cancer } \\
\quad(n=156), \mathrm{n}(\%)\end{array}$} \\
\hline No & $36(52.2)$ & $49(56.3)$ \\
\hline Yes & $33(47.8)$ & $37(42.6)$ \\
\hline Unknown & $\ldots$ & $1(1.1)$ \\
\hline \multicolumn{3}{|l|}{ SCT, n $(\%)^{\mathrm{c}}$} \\
\hline Allogenic SCT & $\ldots$ & $\ldots$ \\
\hline Autologous SCT & $48(100.0)$ & $24(100.0)$ \\
\hline
\end{tabular}

\begin{tabular}{|c|c|c|c|c|}
\hline \multirow[t]{2}{*}{ Variable } & \multicolumn{2}{|c|}{ Control $(\mathrm{n}=878)$} & \multicolumn{2}{|c|}{ Intervention $(\mathrm{n}=1075)$} \\
\hline & Pre mean (SD) & Post mean (SD) & Pre mean (SD) & Post mean (SD) \\
\hline \multicolumn{5}{|l|}{ Depression $^{\mathrm{d}}$} \\
\hline HADS depression subscale, range $0-21(\mathrm{k}=7)$ & $4.1(3.5)$ & $3.6(3.2)$ & $4.2(3.6)$ & $3.4(3.3)$ \\
\hline CES-D total score, range $(\mathrm{k}=2)$ & $36.8(12.1)$ & $34.7(13.0)$ & $37.5(9.8)$ & $36.5(9.8)$ \\
\hline POMS depression subscale, range $0-60(\mathrm{k}=3)$ & $6.4(10.5)$ & $6.9(10.2)$ & $7.3(8.6)$ & $6.3(7.0)$ \\
\hline BDI total score, range $0-63(\mathrm{k}=1)$ & $8.1(4.2)$ & $8.7(5.1)$ & $11.3(6.5)$ & $6.4(7.1)$ \\
\hline WHQ depression subscale, range $0-1(\mathrm{k}=1)$ & $0.49(0.33)$ & $0.45(0.31)$ & $0.35(0.34)$ & $0.22(0.24)$ \\
\hline SCL-90 depression subscale, range $0-72(\mathrm{k}=1)$ & $21.4(5.3)$ & $20.4(4.2)$ & $21.3(6.0)$ & $20.3(5.3)$ \\
\hline
\end{tabular}


Table 3 (continued)

\begin{tabular}{|c|c|c|c|c|}
\hline \multirow[t]{2}{*}{ Variable } & \multicolumn{2}{|c|}{ Control $(\mathrm{n}=878)$} & \multicolumn{2}{|c|}{ Intervention $(\mathrm{n}=1075)$} \\
\hline & Pre mean (SD) & Post mean (SD) & Pre mean (SD) & Post mean (SD) \\
\hline HADS anxiety subscale, range $0-21(\mathrm{k}=7)$ & $6.3(4.4)$ & $5.5(4.1)$ & $6.2(4.2)$ & $4.7(3.9)$ \\
\hline STAI state subscale, range $20-80(\mathrm{k}=2)$ & $39.3(9.2)$ & $40.8(11.0)$ & $42.7(9.6)$ & $37.1(10.7)$ \\
\hline POMS anxiety subscale, range $0-36(\mathrm{k}=3)$ & $6.3(6.3)$ & $6.6(6.7)$ & $8.3(6.5)$ & $7.7(6.4)$ \\
\hline WHQ anxiety subscale, range $0-1(\mathrm{k}=1)$ & $0.45(0.30)$ & $0.41(0.33)$ & $0.34(0.25)$ & $0.23(0.27)$ \\
\hline SCL-90 anxiety subscale, range $0-40(\mathrm{k}=1)$ & $13.5(4.2)$ & $12.2(3.3)$ & $13.5(3.8)$ & $12.0(2.9)$ \\
\hline
\end{tabular}

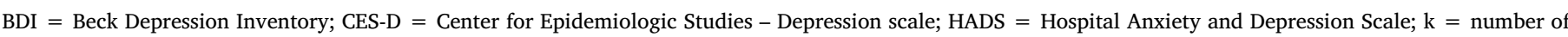

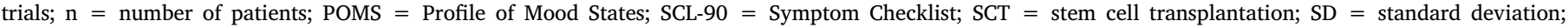
STAI = State Trait Anxiety Index; WHQ = Women's Health Questionnaire;

a Proportion of patients of solid tumors $(n=1881)$.

b Proportion of patients without SCT $(\mathrm{n}=1881)$.

c Proportion of patients with SCT $(n=72)$.

d Higher scores represents higher level of depression and anxiety.

complete outcome reporting, 9 (24\%) described adequate intervention adherence, and $3(8 \%)$ provided information on contamination (Table 1).

IPD was available for 15 RCTs (Armes et al., 2007; Arving et al., 2007; Braamse et al., 2016; Duijts et al., 2012; Ferguson et al., 2012; Gellaitry et al., 2010; Gielissen et al., 2006; Goedendorp et al., 2010; Graves et al., 2003; Heiney et al., 2003; Johansson et al., 2008; Mann et al., 2012; Northouse et al., 2013; Savard et al., 2005; van den Berg et al., 2015) including 1953 patients with cancer, of whom 1075 were randomly allocated to the intervention and 878 to the control group. The mean (SD) age of patients was 55.3 (11.3) years, 78.5\% were female, $68.0 \%$ were married and/or lived with a partner, $27.6 \%$ were highly educated, $66.6 \%$ were diagnosed with breast cancer, and $5.9 \%$ had distant metastatic disease at baseline (Table 3).

\subsection{Effect of CST on depression and anxiety and intervention-related moderators using $A D$ meta-analyses}

After removing outliers (3 RCTs for depression (Badger et al., 2007; Desautels et al., 2018; Manne et al., 2017), 4 RCTs for anxiety (Badger et al., 2007; Garssen et al., 2013; Kangas et al., 2013; Wells-Di Gregorio et al., 2019), CST resulted in a statistically significant reduction in depression $(\mathrm{g}=-0.31,95 \% \mathrm{CI}=-0.40 ;-0.22)$ and anxiety ( $\mathrm{g}=-0.32,95 \% \mathrm{CI}=-0.41 ;-0.24)$ compared to the control group overall (Table 4). The intervention effects on depression were significantly larger for interventions that were delivered face-to-face compared to those delivered via other methods ( $p=.003$ ), for interventions led by a psychologist $(p=.02)$, and for studies that specifically targeted patients with high levels of psychological distress ( $p=.002$, Table 4$)$. Intervention effects on anxiety seemed larger for interventions delivered following treatment $(p=.06)$, that were delivered face-to-face $(p=.10)$, and those targeting patients with high levels of psychological distress ( $\mathrm{p}=.06$ ), but this was not statistically significant (Table 4). Intervention effects on depression and anxiety did not differ significantly across subgroups for intervention strategy, duration, and focus (Table 4).

\subsection{Patient-level moderators evaluated with IPD meta-analyses}

Age significantly moderated intervention effects on anxiety ( $\mathrm{p}=.02$ ), with statistically significant effects of CST in patients aged $<50$ years $(\beta=-0.31,95 \% \mathrm{CI}=-0.44 ;-0.18)$, and $50-70$ years $(\beta=-0.11,95 \% \mathrm{CI}=-0.21 ;-0.00)$, while the effect in patients older than 70 years was not statistically significant $(\beta=-0.02,95 \% \mathrm{CI}=-0.29 ; 0.24)$ (Table 5$)$. For reference, the overall intervention effect on anxiety based on IPD is $-0.17(95 \% \mathrm{CI}=-0.25$; -0.10 , Table 5).

Receiving chemotherapy significantly moderated the effect of CST on depression $(p=.03)$ and anxiety $(p=.05)$ : Reductions in depression $(\beta=-0.16,95 \% \mathrm{CI}=-0.25 ;-0.07)$ and anxiety $(\beta=-0.24,95 \% \mathrm{CI}=-0.33 ;-0.14)$ were statistically significant in patients who received chemotherapy, but not in patients who did not receive chemotherapy. No other demographic and clinical variables significantly moderated the CST effect on depression and anxiety.

\subsection{Representativeness of the IPD sample and publication bias}

Pooled effects of studies with IPD on depression $(\mathrm{p}=.06)$ and anxiety $(p=.47)$ seemed somewhat smaller than the effects of studies without IPD, but differences were not statistically significant (Table 4). Consequently, we found no evidence that the sample of studies with IPD was not a representative sample of published studies. The average effect sizes, however, indicate a slightly underestimation the overall effect.

The Duvall and Tweedie's trim and fill procedure suggested that 9 trials were missing for depression and 7 trials for anxiety, resulting in an adjusted effect size of $-0.21(95 \% \mathrm{CI}=-0.31 ;-0.11)$ for depression and of $-0.23(95 \% \mathrm{CI}=-0.33 ;-0.13)$ for anxiety after adjusting for possible publication bias (Table 2). The Egger's test was statistically significant for depression $(p=.04)$, but not for anxiety $(p=.20)$, indicating a presence of publication bias for depression.

\section{Discussion}

These AD and IPD meta-analyses showed that CST is effective in reducing depression and anxiety in patients with cancer during and after treatment, however, with small overall effects. The findings are in line with results from previous meta-analyses (Cuijpers, van Straten, Andersson, \& van Oppen, 2008; Kalter et al., 2018; Sheard \& Maguire, 1999). Additionally, our meta-analyses found that the effect of CST was moderated by age and chemotherapy treatment, and by method of intervention delivery, leading profession, and whether it was specifically targeted to patients with high levels of psychological distress. These findings have important implications to further improve CST interventions and to target interventions specifically to patients that benefit most, thereby optimizing benefits.

The finding that CST is modestly helpful in reducing depression and anxiety in patients with cancer, regardless of the timing of intervention delivery in the cancer trajectory, is congruent with our previous findings for quality of life (Kalter et al., 2018). However, this may be related to the broader categories that we used for the analyses, or to other factors that may have a larger influence than timing, such as whether the intervention was specifically targeted to patients with distress or not, or the specific cognitions and behaviors that were targeted by the intervention. In contrast to previous studies that found no significant differences in effects between face-to-face interventions and internet-based interventions in reducing anxiety (Kiropoulos et al., 2008) and fatigue (Carlbring, Andersson, Cuijpers, Riper, \& Hedman-Lagerlof, 2018), we found larger effects of face-to-face interventions on depression and we found a similar 


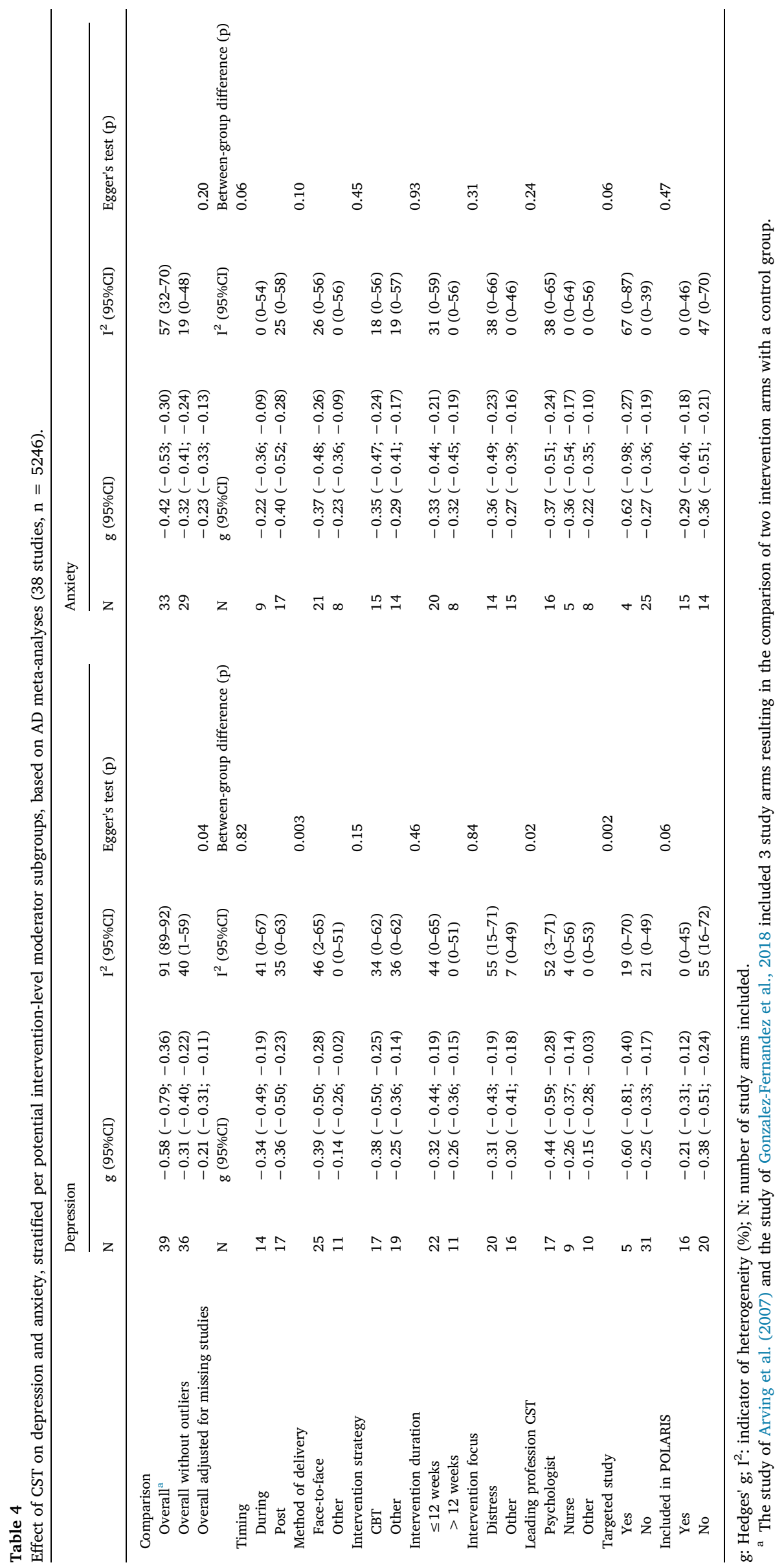


Table 5

Effects of CST on depression and anxiety, stratified by potential patient-level moderator subgroups, based on IPD meta-analyses (15 studies).

\begin{tabular}{|c|c|c|c|c|}
\hline \multirow[t]{2}{*}{ Effects of CST } & \multirow{2}{*}{$\frac{\text { Depression } \beta(95 \% \mathrm{CI})}{-0.12(-0.19 ;-0.05)}$} & \multirow[t]{2}{*}{$\chi^{2}[\mathrm{df}], \mathrm{p}$-value } & \multirow{2}{*}{$\frac{\text { Anxiety } \beta(95 \% \mathrm{CI})}{-0.17(-0.25 ;-0.10)}$} & \multirow[t]{2}{*}{$\chi^{2}[\mathrm{df}], \mathrm{p}$-value } \\
\hline & & & & \\
\hline Age, years & & $2.37[1], 0.12$ & & $5.14[1], 0.02^{*}$ \\
\hline \multicolumn{5}{|l|}{ Age categories } \\
\hline$<50$ years & $\ldots$ & & $-0.31(-0.44 ;-0.18)^{*}$ & \\
\hline $50-70$ years & $\ldots$ & & $-0.11(-0.21 ;-0.00)^{*}$ & \\
\hline$\geq 70$ years & $\ldots$ & & $-0.02(-0.29 ; 0.24)$ & \\
\hline Gender & & $1.50[1], 0.22$ & & $0.79[1], 0.37$ \\
\hline Marital status & & $0.35[1], 0.55$ & & $0.69[1], 0.41$ \\
\hline Education level & & $0.29[1], 0.59$ & & $0.03[1], 0.86$ \\
\hline Type of cancer & & $2.49[6], 0.87$ & & $5.08[6], 0.53$ \\
\hline Distant metastasis at baseline & & $0.18[1], 0.67$ & & $1.79[1], 0.18$ \\
\hline Baseline value of outcome $^{\mathrm{a}}$ & & $1.84[1], 0.18$ & & $0.99[1], 0.32$ \\
\hline Surgery & & $0.46[1], 0.50$ & & $1.98[1], 0.16$ \\
\hline Chemotherapy & & $4.50[1], 0.03^{*}$ & & $3.85[1], 0.05^{*}$ \\
\hline No & $-0.05(-0.17 ; 0.07)$ & & $-0.08(-0.21 ; 0.05)$ & \\
\hline Yes & $-0.16(-0.25 ;-0.07)^{*}$ & & $-0.24(-0.33 ;-0.14)^{*}$ & \\
\hline Radiotherapy & & $0.09[1], 0.76$ & & $0.44[1], 0.50$ \\
\hline Hormone Breast & & $0.10[1], 0.75$ & & $0.02[1], 0.89$ \\
\hline Hormone Prostate & & $0.96[1], 0.33$ & & $2.58[1], 0.11$ \\
\hline
\end{tabular}

Regression coefficients $(\beta), 95 \%$ confidence intervals (CI), and Chi-square test with corresponding degrees of freedom and $p$-values are presented.

$* p<.05$.

a Baseline depression as moderator for outcome depression, baseline anxiety as moderator for outcome anxiety.

trend for anxiety. Particularly interventions led by a psychologist showed the largest benefits on depression. This indicates that, for optimal effectiveness of the intervention, it is important that the intervention is delivered by psychologists, and preferably face-to-face. Finally, we found that only a minority of RCTs specifically selected patients with depression or anxiety at study entry, but those that did showed substantially larger effects. This is in line with findings from previous reviews of studies targeting patients with higher levels of depression or anxiety at baseline (van der Meulen et al., 2015; Williams \& Dale, 2006), that showed significantly larger reductions in depression and anxiety. It clearly highlights that, to optimize effectiveness and cost-effectiveness of CST, it is important to target patients that need it the most. However, our results did not support the moderator effect of baseline depression or anxiety, which may be explained by the low levels of depression or anxiety in the studies with IPD, as they were not targeted specifically to patients with high levels of distress.

Our results did not yield any evidence that other intervention characteristics such as intervention strategy (cognitive behavior therapy versus other strategies like problem-solving therapy and stress management training), or intervention focus (psychological distress versus other outcomes like fatigue and insomnia) moderated the effects of CST on depression and anxiety. For some analyses on potential moderators, we needed to make broad categories for statistical power, but the categories may have been too heterogeneous. Therefore, to gain additional insight into which intervention characteristics are more or less important for reducing depression and anxiety among patients with cancer, future studies need to align study characteristics (e.g., distress measure and eligibility criteria) or to directly compare different intervention characteristics while keeping others similar.

With respect to patient-related moderators, in line with our previous publication on quality of life (Kalter et al., 2018), the analyses on IPD showed that younger patients had larger benefit from CST. This may be explained by higher supportive care needs (and thus more room for improvement) in younger patients compared to older patients (Kalter et al., 2018; Linden, Vodermaier, MacKenzie, \& Greig, 2012; O'Hea et al., 2016; Schuurhuizen, Braamse, Konings, Verheul, \& Dekker, 2019; Simning, Conwell, Mohile, \& van Wijngaarden, 2014). On the other hand, older patients with cancer-related depression or anxiety may have less or other specific or (supportive) care needs compared to younger patients that are not, or only partly, met by CST (Kalter et al., 2018). Further research is needed to identify the specific supportive care needs of the older cancer patient population experiencing depression and anxiety.

We did not observe any moderating effects of sex in our study. This is in line with our IPD meta-analyses focusing on quality of life (Kalter et al., 2018). Overall, findings of previous descriptive studies have been mixed. Some studies report that depression (Albert, 2015; Hong \& Tian, 2014) and anxiety (Linden et al., 2012) are generally more prevalent in women than in men, and therefore, women could benefit more from these interventions. However, another study among patients with various cancer types found that men more often experience anxiety than women (Hong \& Tian, 2014).

In line with our previous meta-analysis on quality of life, our study found a moderator effect of chemotherapy, where patients who received chemotherapy experienced larger reductions in depression and anxiety after CST compared to those who did not. This may be related to higher levels of depression and anxiety associated with chemotherapy (Kyranou et al., 2014; Yang et al., 2016). As hormone therapy has also been associated with increased levels of depression and anxiety (Sharpley, Christie, \& Bitsika, 2014), larger effects of CST were also expected in patients who received hormone therapy as part of their treatment compared to those who did not. This, however, did not prove to be the case in our study. The lack of moderator effects of other treatment types may result from our dichotomisation of each treatment into whether patients received treatment or not, which does not take into account the intensity of treatment. Due to the differences in data collected and provided by the original studies, we were unable to specify types of surgery (e.g., mastectomy or lumpectomy), or types of chemotherapy, radiotherapy or hormone therapy in further detail. Since the cancer diagnosis and its treatment are closely related, the effect of treatment types should be examined within more homogenous groups of patients.

\section{Strengths and limitations}

A strength of this study is that AD and IPD meta-analyses were combined which provided us the unique opportunity to use the advantages of both approaches. The strength of the $\mathrm{AD}$ meta-analysis is the ability to include a larger number of RCTs compared with an IPD meta-analysis, which provided a larger database to test differences in intervention characteristics at the study level. In addition, the strength of the IPD-meta-analysis is the ability to test demographic, clinical, and psychosocial characteristics as effect moderators at the patient level 
using a large sample, and to conduct stratified analyses with sufficient power. However, although we maximised power for each analyses by combining both types of meta-analyses, some study-level moderators may still have been underpowered due to small subgroups, or loss of information by forming subgroups.

A limitation of IPD meta-analysis is the need to obtain the original data for an RCT to be included in the analysis. This may result in retrieval bias, since IPD can often only be obtained from a subset of studies. However, there was no significant difference in effects between studies with and without IPD, indicating our IPD sample was representative of the studies identified in the $\mathrm{AD}$ meta-analysis. Nevertheless, overall, there seemed to be a publication bias for depression; studies with larger effects on depression appeared more likely to be published, which may have resulted in an overestimation of the effect of CST on depression. Other possible biases that may have been present in the RCTs under investigation could be related to the absence of information on adherence to the intervention and potential contamination of the control group. Finally, our investigation was limited to the short-term intervention effects of CST as very few RCTs examined longer term effects. Research into long-term effects of CSI for depression and anxiety is therefore warranted.

In conclusion, CST significantly reduces symptoms of depression and anxiety during and after cancer treatment; however, the overall effects are small, and possibly of limited clinical relevance. CST effects were significantly larger in patients who were younger, and received chemotherapy as part of their cancer treatment, as well as in studies in which the intervention was delivered face to face and by a psychologist. Significant and clinically meaningful benefits can be obtained by targeting patients with high levels of psychological distress. Further research is needed to unravel differences in effects between different intervention-characteristics in more detail.

\section{Role of funding source}

The study was funded by the A Bas Mulder Award, a personal grant of the Alpe d'HuZes Foundation/Dutch Cancer Society (VU 2011-5045) that was granted to L.M. Buffart. The Dutch Cancer Society had no involvement in the study design, collection, analysis or interpretation of the data, writing the manuscript, or the decision to submit the manuscript for publication.

\section{Contributors}

Buffart, Brug, Verdonck-de Leeuw are members of the steering committee of POLARIS. Courneya, Newton, Jacobsen and Aaronson are members of the international advisory board. These authors contributed to the concept and the design of the study. Buffart, Kalter, Schreurs, and Abrahams were involved with data collection, data analyses, and drafting the manuscript.

Aaronson, Armes, Arving, Braamse, Brandberg, Dekker, Fergusen, Gielissen, Glimelius, Goedendorp, Graves, Heiney, Horne, Hunter, Johansson, Northouse, Oldenburg, Prins, Savard, van Beurden, van den Berg, and Knoop are Principal investigators of the randomized controlled trials of which the data are pooled for the current study, and have consequently contributed to the study concept, design, and conduct of the trial that they were responsible for. All authors have critically reviewed the manuscript and approved the final version.

\section{Declaration of Competing Interest}

None declared.

\section{Acknowledgements}

None.

\section{Appendix A. Search terms used in pubmed search}

\section{\#1 neoplasms}

"neoplasms"[Mesh] OR metastas*[tiab] OR neoplas* [tiab] OR tumor" [tiab] OR cancer" [tiab] OR.

tumor[tiab] OR tumora*[tiab] OR tumorb*[tiab] OR tumorc*[tiab] OR tumord*[tiab] OR tumore*[tiab] OR tumorf*[tiab] OR tumorg*[tiab] OR tumorh*[tiab] OR tumori*[tiab] OR tumork*[tiab] OR tumorl*[tiab] OR tumorm*[tiab] OR tumorn*[tiab] OR tumoro*[tiab] OR tumorp*[tiab] OR tumorr*[tiab] OR tumors*[tiab] OR tumort*[tiab] OR tumoru*[tiab] OR tumorv*[tiab] OR tumorw*[tiab] OR tumorx*[tiab] OR tumory*[tiab] OR tumorz*[tiab] OR tumor**[tiab] OR tumor1[tiab].

\section{\#2 psychosocial therapy}

"Social Support"[Mesh] OR "Behavior Therapy"[Mesh] OR "cognitive therapy"[Mesh] OR "Mind-body therapies" [Mesh] OR "relaxation therapy"[Mesh] OR "counseling"[Mesh] OR "biofeedback, psychology"[Mesh] OR "guideline adherence"[Mesh] OR "patient compliance"[Mesh] OR "patient education as topic"[Mesh] OR "Health promotion"[Mesh] OR "Health education"[Mesh] OR "health behavior"[Mesh] OR "Reinforcement (Psychology)"[Mesh] OR "social support" [tiab] OR "Behavior therapy"[tiab] OR "cognitive therapy"[tiab] OR "Mind-body therapies"[tiab] OR counselor* [tiab] OR "psychology biofeedback"[tiab] OR "guideline adherence"[tiab] OR "patient compliance"[tiab] OR "patient education as topic" [tiab] OR "Health promotion"[tiab] OR "Health education"[tiab] OR "health behavior"[tiab] OR "Reinforcement (Psychology)"[tiab] OR alternative therap*[tiab] OR "Psychophysiology"[tiab] OR "behavior training"[tiab] OR "behavior treatment"[tiab] OR "desensitization"[tiab] OR "CBT" [tiab] OR cognitive behavior therap" [tiab] OR cognitive behavior treatment*[tiab] OR cognitive behavioural therap*[tiab] OR cognitive behavioural treatment*[tiab] OR cognitive behavior therap*[tiab] OR cognitive behavior treatment*[tiab] OR cognitive behavioural therap*[tiab] OR cognitive behavioural treatment*[tiab] OR "anthroposophy" [tiab] OR "complementary medicine"[tiab] OR complementary therap*[tiab] OR mind-body relation*[tiab] OR mind-body therap*[tiab] OR mind body techniq*[tiab] OR mind body therap*[tiab] OR "naturopathy orthomolecular medicine" [tiab] OR polarity thera*[tiab] OR reflexotherap*[tiab] OR spiritual therap*[tiab] OR "mind-body and relaxation techniques"[tiab] relaxation therap*[tiab] OR client centered therap*[tiab] OR nondirective therap*[tiab] OR "biofeedback (psychology)"[tiab] OR psychoneuroimmunolog*[tiab] OR psychophysiologic respons" [tiab] OR "patient adherence"[tiab] OR "treatment compliance"[tiab] OR health behav*[tiab] OR health promoting behav*[tiab] OR health related behav*[tiab] OR "conditioning" [tiab] OR "differential reinforcement"[tiab] OR "knowledge of results (psychology)" [tiab].

\section{\#3 Outcome measures}

depressive OR anxiety OR distress.

\#4 Randomized controlled trials

"randomized controlled trial" [pt] OR "controlled clinical trial" [pt] OR "randomized controlled trials" [mh] OR "random allocation" [mh] OR "double-blind method" [mh] OR "single-blind method" [mh] OR "clinical trial" [pt] OR "clinical trials" [mh] OR "clinical trial" [tw] OR ( (singl* [tw] OR doubl* [tw] OR trebl* [tw] OR tripl* [tw]) AND (mask* [tw] OR blind* [tw])) OR "latin square" [tw] OR placebos [mh] OR placebo* [tw] OR random* [tw] OR research design [mh:noexp] OR comparative study [pt] OR evaluation studies [pt] OR follow-up studies [mh] OR prospective studies [mh] OR cross-over studies [mh] OR control[tw] OR controll*[tw] OR prospectiv* [tw] OR volunteer* [tw]) NOT (animal [mh] NOT human [mh]).

(RCT Filter kort: "randomized controlled trial"[pt] OR "controlled clinical trial" [pt] OR "randomized"[tiab] OR "placebo"[tiab] OR "drug therapy" [sh] OR "randomly"[tiab] OR "trial"[tiab] OR "groups"[tiab]) \#5 Adult (not child)

(("Adolescent"[Mesh] OR "Child"[Mesh] OR "Infant"[Mesh] OR 
adolescen*[tiab] OR child*[tiab] OR schoolchild*[tiab] OR infant*[tiab] OR girl*[tiab] OR boy*[tiab] OR teen[tiab] OR teens[tiab] OR teenager*[tiab] OR youth*[tiab] OR pediatr*[tiab] OR paediatr*[tiab] OR puber*[tiab]) NOT ("Adult"[Mesh] OR adult*[tiab] OR man[tiab] OR men[tiab] OR woman[tiab] OR women[tiab]))

\section{References}

Aguado Loi, C. X., Nesman, T. M., Xu, P., Taylor, T. R., McMillan, S., Krischer, J. P., .. Huegel, V. (2017). A self-administered stress management intervention for hispanic patients undergoing cancer chemotherapy. Journal of Immigrant and Minority Health, $19,1121-1131$.

Aguado Loi, C. X., Taylor, T. R., McMillan, S., Gross-King, M., Xu, P., \& Shoss, M. K. (2012). Use and helpfulness of self-administered stress management therapy in patients undergoing cancer chemotherapy in community clinical settings. Journal of Psychosocial Oncology, 30.

Albert, P. R. (2015). Why is depression more prevalent in women? Journal of Psychiatry \& Neuroscience, 40.

Andersson, G., \& Cuijpers, P. (2009). Internet-based and other computerized psychological treatments for adult depression: a meta-analysis. Cognitive Behaviour Therapy, 38, 196-205.

Armes, J., Chalder, T., Addington-Hall, J., Richardson, A., \& Hotopf, M. (2007). A randomized controlled trial to evaluate the effectiveness of a brief, behaviorally oriented intervention for cancer-related fatigue. Cancer, 110, 1385-1395.

Arrieta, O., Angulo, L. P., Nunez-Valencia, C., Dorantes-Gallareta, Y., Macedo, E. O., Martinez-Lopez, D., ... Onate-Ocana, L. F. (2013). Association of depression and anxiety on quality of life, treatment adherence, and prognosis in patients with advanced non-small cell lung cancer. Annals of Surgical Oncology, 20, 1941-1948.

Arving, C., Sjöden, P., Bergh, J., Hellbom, M., Johansson, B., Glimelius, B., \& Brandberg, Y. (2007). Individual psychosocial support for breast cancer patients. Cancer Nursing, 30, E10-E19.

Badger, T., Segrin, C., Dorros, S., Meek, P., \& Lopez, A. (2007). Depression and anxiety in women with breast cancer and their partners. Nursing Research, 56, 44-53.

Badger, T., Segrin, C., Figueredo, A., Harrington, J., Sheppard, K., Passalacqua, S., .. Bishop, M. (2013). Who benefits from a psychosocial counselling versus educational intervention to improve psychological quality of life in prostate cancer survivors? Psychology \& Health, 28, 336-354.

Ballesio, A., Aquino, M., Feige, B., Johann, A., Kyle, S., Spiegelhalder, K., ... Baglioni, C. (2017). The effectiveness of behavioural and cognitive behavioural therapies for insomnia on depressive and fatigue symptoms: A systematic review and network meta-analysis. Sleep Medicine Reviews, 1-16.

Barber, B., Dergousoff, J., Nesbitt, M., Mitchell, N., Harris, J., O'Connell, D., ... Seikaly, H. (2015). Depression as a predictor of postoperative functional performance status (PFPS) and treatment adherence in head and neck cancer patients: a prospective study. Journal of Otolaryngology - Head \& Neck Surgery, 44, 38.

Barsevick, A. M., Irwin, M., Hinds, P., Miller, A., Berger, A., Jacobsen, P., ... Cella, D. (2013). Recommendations for high-priority research on cancer-related fatigue in children and adults. Journal of the National Cancer Institute, 105, 1432-1440.

van den Berg, S., Gielissen, M., Custers, J., van der Graaf, W., Ottevanger, P., \& Prins, J. (2015). BREATH: Web-based self-management for psychological adjustment after primary breast cancer - Results of a multicenter randomized controlled trial. Journal of Clinical Oncology, 33, 2763-2771.

Berlin, J., Santanna, J., Schmid, C., Szczech, L., \& Feldman, H. (2002). Individual patientversus group-level data meta-regressions for the investigation of treatment effect modifiers: ecological bias rears its ugly head. Statistics in Medicine, 21, 371-387.

van den Beuken-van Everdingen, M., Hochstenback, L., Joosten, E., Tjan-Heijnen, V., \& Janssen, D. (2016). Update on prevalence of pain in patients with cancer: systematic review and meta-analysis. Journal of Pain and Symptom Management, 51, 1070-1090.

Braamse, A., van Meijel, B., Visser, O., Boenink, A., Cuijpers, P., Eeltink, C., ... Dekker, J. (2016). A randomized clinical trial on the effectiveness of an intervention to treat psychological distress and improve quality of life after autologous stem cell transplantation. Annals of Hematology, 95, 105-114.

Buffart, L., Kalter, J., Chinapaw, M., Heymans, M., Aaronson, N., Courneya, K., ... Brug, J. (2013). Predicting OptimaL cAncer RehabIlitation and Supportive care (POLARIS): rationale and design for meta-analyses of individual patient data of randomized controlled trials that evaluate the effect of physical activity and psychosocial interventions on health-related quality of life in cancer survivors. Systematic Reviews, 2.

Buffart, L., Kalter, J., Sweegers, M., Courneya, K., Newton, R., Aaronson, N., ... Brug, J. (2017). Effects and moderators of exercise on quality of life and physical function in patients with cancer: An individual patient data meta-analysis of 34 RCTs. Cancer Treatment Reviews, 52, 91-104.

Butow, P. N., Turner, J., Gilchrist, J., Sharpe, L., Smith, A. B., Fardell, J. E., ... Thewes, B. (2017). Randomized trial of conquerfear: a novel, theoretically based psychosocial intervention for fear of cancer recurrence. Journal of Clinical Oncology, 35, 4066-4077.

Carlbring, P., Andersson, G., Cuijpers, P., Riper, H., \& Hedman-Lagerlof, E. (2018) Internet-based vs. face-to-face cognitive behavior therapy for psychiatric and somatic disorders: an updated systematic review and meta-analysis. Cognitive Behaviour Therapy, 47, 1-18.

Cleeland, C., Mendoza, T., Wang, X., Chou, C., Harle, M., Morrissey, M., \& Engstorm, M. (2000). Assessing symptom distress in cancer patients: the M.D. Anderson symptom inventory. Cancer, 89, 1634-1646.

Cohen, J. (2013). Statistical Power Analysis for the Behavioral Sciences (ed Revised edition).
Academic press.

Courneya, K., \& Friedenreich, C. (2007). Physical activity and cancer control. Seminars in Oncology Nursing, 23, 242-252.

Cuijpers, P. (2016). Meta-analysis in mental health research. A pratical guide. Amsterdam: VU University Amsterdam.

Cuijpers, P., van Straten, A., Andersson, G., \& van Oppen, P. (2008). Psychotherapy for depression in adults: a meta-analysis of comparative outcome studies. Journal of Consulting and Clinical Psychology, 76, 909-922.

Cunningham, A. (1995). Group psychological therapy for cancer patients. A brief discussion of indications for its use, and the range of interventions available. Support Care Cancer, 3, 244-247.

Dauchy, S., Dolbeault, S., \& Reich, M. (2013). Depression in cancer patients. European Journal of Cancer Care, 11, 205-215.

Desautels, C., Savard, J., Ivers, H., Savard, M. H., \& Caplette-Gingras, A. (2018). Treatment of depressive symptoms in patients with breast cancer: A randomized controlled trial comparing cognitive therapy and bright light therapy. Health Psychology, 37, 1-13.

Dirksen, S., \& Epstein, D. (2008). Efficacy of an insomnia intervention on fatigue, mood and quality of life in breast cancer survivors. Journal of Advanced Nursing, 61, 664-675.

do Carmo, T. M., Paiva, B. S. R., de Oliveira, C. Z., Nascimento, M. S. A., \& Paiva, C. E. (2017). The feasibility and benefit of a brief psychosocial intervention in addition to early palliative care in patients with advanced cancer to reduce depressive symptoms: a pilot randomized controlled clinical trial. BMC Cancer, 17, 564.

Downe-Wamboldt, B. L., Butler, L. J., Melanson, P. M., Coulter, L. A., Singleton, J. F., Keefe, J. M., \& David, G. (2007). The effects and expense of augmenting usual cancer clinic care with telephone problem-solving counseling. Cancer Nursing, 30, 441-453.

Duijts, S. F., van Beurden, M., Oldenburg, H. S., Hunter, M. S., Kieffer, J. M., Stuiver, M. M., Gerritsma, M. A., Menke-Pluymers, M. B., Plaisier, P. W., Rijna, H., Lopes Cardozo, A. M., Timmers, G., van der Meij, S., van der Veen, H., Bijker, N., de WidtLevert, L. M., Geenen, M. M., Heuff, G., van Dulken, E. J., Boven, E., \& Aaronson, N. K. (2012). Efficacy of cognitive behavioral therapy and physical exercise in alleviating treatment-induced menopausal symptoms in patients with breast cancer: results of a randomized, controlled, multicenter trial. J Clin Oncol. 30(33), 4124-4133.

Duval, S., \& Tweedie, R. (2000). Trim and fill: A simple funnel-plot-based method of testing and adjusting for publication bias in meta-analysis. Biometrics, 56, 455-463.

Faller, H., Schuler, M., Richard, M., Heckl, U., Weis, J., \& Küffner, R. (2013). Effects of psycho-oncologic interventions on emotional distress and quality of life in adult patients with cancer: systematic review and meta-analysis. Journal of Clinical Oncology, 31, 782-793.

Ferguson, R., McDonald, B., Rocque, M., Furstenberg, C., Horrigan, S., Ahles, T., \& Saykin, A. (2012). Development of CBT for chemotherapy-related cognitive change: results of a waitlist control trial. Psychooncology, 21, 176-186.

Garssen, B., Boomsma, M. F., De Jager Meezenbroek, E., Porsild, T., Berkhof, J., Berbee, M., ... Beelen, R. H. J. (2013). Stress management training for breast cancer surgery patients. Psycho-Oncology, 22, 572-580.

Gellaitry, G., Peters, K., Bloomfield, D., \& Horne, R. (2010). Narrowing the gap: the effects of an expressive writing intervention on perceptions of actual and ideal emotional support in women who have completed treatment for early stage breast cancer. Psychooncology, 19, 77-84.

Gielissen, M., Verhagen, S., Witjes, F., \& Bleijenberg, G. (2006). Effects of cognitive behavior therapy in severely fatigued disease-free cancer patients compared with patients waiting for cognitive behavior therapy: A randomized controlled trial. Journal of Clinical Oncology, 24, 4882-4887.

Goedendorp, M. M., Peters, M. E. W. J., Gielissen, M., Witjes, J. A., Leer, J. W., Verhagen, C. A., \& Blijenberg, G. (2010). Is increasing physical activity necessary to diminish fatigue during cancer treatment? Comparing cognitive behavior therapy and a brief nursing intervention with usual care in a multicenter randomized controlled trial. Oncologist, 15, 1122-1132.

Gonzalez-Fernandez, S., Fernandez-Rodriguez, C., Paz-Caballero, M. D., \& Perez-Alvarez, M. (2018). Treating anxiety and depression of cancer survivors: Behavioral activation versus acceptance and commitment therapy. Psicothema, 30, 14-20.

Graves, K., Carter, C., Anderson, E., \& Winett, R. (2003). Quality of life pilot intervention for breast cancer patients: Use of social cognitive theory. Palliative \& Supportive Care, $1,121-134$.

Greer, J. A., Traeger, L., Bemis, H., Solis, J., Hendriksen, E. S., Park, E. R., ... Safren, S. A. (2012). Pilot randomized controlled trial of brief cognitive-behavioral therapy for anxiety in patients with terminal cancer. Oncologist, 17, 1337-1345.

Guo, Z., Tang, H., Li, H., Feng, K., Huang, Y., Bu, Q., \& Jiang, W. (2013). The benefits of psychosocial interventions for cancer patients undergoing radiotherapy. Health and Quality of Life Outcomes, 11.

Hedges, L., \& Olkin, I. (1985). Statistical Method for Meta-Analysis. San Diego, CA: Academic press.

Heiney, S., McWayne, J., Hurley, T., Lamb, L., Bryant, L., Butler, W., \& Godder, K. (2003). Efficacy of therapeutic group by telephone for women with breast cancer. Cancer Nursing, 26, 439-447.

Helgeson, V., Lepore, S., \& Eton, D. (2006). Moderators of the benefits of psychoeducational interventions for men with prostate cancer. Health Psychology, 25, 348-354.

Heron-Speirs, H., Baken, D., \& Harvey, S. (2012). Moderators of psycho-oncology therapy effectiveness: Meta-analysis of socio-demographic and medical patient characteristics. Clinical Psychology: Science and Practice, 19, 402-416.

Heron-Speirs, H., Harvey, S., \& Baken, D. (2013). Moderators of psycho-oncology therapy effectiveness: meta-analysis of therapy characteristics. Journal of Psychosocial Oncology, 31, 617-641.

Higgins, J., Thompson, S., Deeks, J., \& Altman, D. (2003). Measuring inconsistency in meta-analyses. BMJ, 327, 557-560. 
Higgins, J. P., Altman, D. G., Gotzsche, P. C., Juni, P., Moher, D., Oxman, A. D., .. Cochrane Statistical Methods, G. (2011). The Cochrane Collaboration's tool for assessing risk of bias in randomised trials. BMJ, 343, d5928.

Hong, J. S., \& Tian, J. (2014). Prevalence of anxiety and depression and their risk factors in Chine cancer patients. Support Care Cancer, 22, 452-459.

Hutter, N., Vogel, B., Alexander, T., Baumeister, H., Helmes, A., \& Bengel, J. (2013). Are depression and anxiety determinants or indicators of quality of life in breast cancer patients? Psychology, Health \& Medicine, 18, 412-419.

Jacobsen, P., \& Jim, H. (2008). Psychosocial interventions for anxiety and depression in adult cancer patients: Achievements and Challenges. CA: a Cancer Journal for Clinicians, 58, 214-230.

Johansson, B., Brandberg, Y., Hellbom, M., Persson, C., Petersson, L., Berglund, G., \& Glimelius, B. (2008). Health-related quality of life and distress in cancer patients: results from a large randomised study. British Journal of Cancer, 99, 1975-1983.

Kalter, J., Sweegers, M. G., Verdonck-de Leeuw, I. M., Brug, J., \& Buffart, L. M. (2019). Development and use of a flexible data harmonization platform to facilitate the harmonization of individual patient data for meta-analyses. BMC Research Notes, 12, 164.

Kalter, J., Verdonck-de Leeuw, I. M., Sweegers, M. G., Aaronson, N. K., Jacobsen, P. B., Newton, R. U., ... Buffart, L. M. (2018). Effects and moderators of psychosocial interventions on quality of life, and emotional and social function in patients with cancer: An individual patient data meta-analysis of 22 RCTs. Psychooncology, 27, $1150-1161$.

Kangas, M., Milross, C., Taylor, A., \& Bryant, R. (2013). A pilot randomized controlled trial of a brief early intervention for reducing posttraumatic stress disorder, anxiety and depressive symptoms in newly diagnosed head and neck cancer patients. PsychoOncology, 22, 1665-1673.

Kiropoulos, L. A., Klein, B., Austin, D. W., Gilson, K., Pier, C., Mitchell, J., \& Ciechomski, L. (2008). Is Internet-based CBT for panic disorder and agoraphobia as effective as face-to-face CBT? Journal of Anxiety Disorders, 22, 1273-1284.

Krebber, A., Buffart, L., Kleijn, G., Riepma, I., de Bree, R., Leemans, C., ... Verdonck-de Leeuw, I. (2014). Prevalence of depression in cancer patients: a meta-analysis of diagnostic interviews and self-report instruments. Psychooncology, 23, 121-130.

Kurtz, M. E., Kurtz, J. C., Given, C. W., \& Given, B. (2005). A randomized, controlled trial of a patient/caregiver symptom control intervention: Effects on depressive symptomatology of caregivers of cancer patients. Journal of Pain and Symptom Management, 30, 112-122.

Kyranou, M., Puntillo, K., Aouizerat, B. E., Paul, S. M., Cooper, B. A., West, C., ... Elboim, C. (2014). Trajectories of depressive symptoms in women prior to and for 6 months after breast cancer surgery. Journal of Applied Biobehavioral Research, 19, 79-105.

Linden, W., Vodermaier, A., MacKenzie, R., \& Greig, D. (2012). Anxiety and depression after cancer diagnosis: prevalence rates by cancer type, gender, and age. Journal of Affective Disorders, 141, 343-351.

Lyman, G. H., \& Kuderer, N. M. (2005). The strengths and limitations of meta-analyses based on aggregate data. BMC Medical Research Methodology, 5.

Mann, E., Smith, M., Hellier, J., Balabanovic, J., Hamed, H., Grunfeld, E., \& Hunter, M. (2012). Cognitive behavioural treatment for women who have menopausal symptoms after breast cancer treatment (MENOS 1): a randomised controlled trial. The Lancet Oncology, 13, 309-318.

Manne, S. L., Virtue, S. M., Ozga, M., Kashy, D., Heckman, C., Kissane, D. W., .. Rodriquez, L. (2017). A comparison of two psychological interventions for newlydiagnosed gynecological cancer patients. Gynecologic Oncology, 144, 354-362.

Matthews, H., Grunfeld, E., \& Turner, A. (2016). The efficacy of interventions to improve psychosocial outcomes following surgical treatment for breast cancer: a systematic review and meta-analysis. Psycho-Oncology, 26, 593-607.

van der Meulen, I. C., May, A. M., Rob, J., de Leeuw, J., Koole, R., Oosterom, M., ... Ros, W. (2015). Moderators of the response to a nurse-led psychosocial intervention to reduce depressive symptoms in head and neck cancer patients. Support Care Cancer, $23,2417-2426$

Mitchell, A., Chan, M., Bhatti, H., Halton, M., Grassi, L., Johansen, C., \& Meader, N. (2011). Prevalence of depression, anxiety, and adjustment disorder in oncological, haematological, and palliative-care settings: a meta-analysis of 94 interview-based studies. The Lancet Oncology, 12, 160-174.

Moher, D., Liberati, A., Tetzlaff, J., \& Altman, D. (2009). Preferred reporting items for systematic reviews and meta-analyses: The PRISMA statement. PLoS Medicine, 6.

Napoles, A., Ortiz, C., Santoyo-Olsson, J., Stewart, A. L., Gregorich, S., Lee, H. E., ... Luce, J. (2015). Nuevo Amanecer: results of a randomized controlled trial of a communitybased, peer-delivered stress management intervention to improve quality of life in Latinas with breast cancer. American Journal of Public Health, 105, e55-e63.

Nikbakhsh, N., Moudi, S., Abbasian, S., \& Khafri, S. (2014). Prevalence of depression and anxiety among cancer patients. Caspian Journal of Internal Medicine, 5, 167-170.

Northouse, L., Mood, D., Schafenacker, A., Kalemkerian, G., Zalupski, M., LoRusso, P., .. Kershaw, T. (2013). Randomized clinical trial of a brief and extensive dyadic intervention for advanced cancer patients and their family caregivers. Psychooncology, 22, $555-563$.

O'Hea, E. L., Monahan, B. R., Cutillo, A., Person, S. D., Grissom, G., \& Boudreaux, E. D. (2016). Predictors of psychological distress and interest in mental health services in individuals with cancer. Journal of Health Psychology, 21, 1145-1156.

Pirl, W. (2004). Evidence report on the occurrence, assessment, and treatment of depression in cancer patients. Journal of the National Cancer Institute. Monographs, 32.

Ream, E., Gargaro, G., Barsevick, A. M., \& Richardson, A. (2015). Management of cancerrelated fatigue during chemotherapy through telephone motivational interviewing: modeling and randomized exploratory trial. Patient Education and Counseling, 98, 199-206.

Ren, W., Qiu, H., Yang, Y., Zhu, X., Zhu, C., Mao, G., ... He, J. (2019). Randomized controlled trial of cognitive behavioural therapy for depressive and anxiety symptoms in Chinese women with breast cancer. Psychiatry Research, 271, 52-59.

Riley, R., Lambert, P., \& Abo-Zaid, G. (2010). Meta-analysis of individual participant data: rationale, conduct and reporting. BMJ, 340.

Savard, J., Simard, S., Ivers, H., \& Morin, C. (2005). Randomized study on the efficacy of cognitive-behavioral therapy for insomnia secondary to breast cancer, part I: Sleep and psychological effects. Journal of Clinical Oncology, 23, 6083-6096.

Schneider, S., Moyer, A., Knapp-Oliver, S., Sohl, S., Cannella, D., \& Targhetta, V. (2010). Pre-intervention distress moderates the efficacy of psychosocial treatment for cancer patients: a meta-analysis. Journal of Behavioral Medicine, 33, 1-14.

Schuurhuizen, C., Braamse, A. M. J., Konings, I., Verheul, H. M. W., \& Dekker, J. (2019). Predictors for use of psychosocial services in patients with metastatic colorectal cancer receiving first line systemic treatment. BMC Cancer, 19, 115.

Sharpley, C., Christie, D., \& Bitsika, V. (2014). Do hormone treatments for prostate cancer cause anxiety and depression? International Journal of Clinical Oncology, 19, 523-530.

Sheard, T., \& Maguire, P. (1999). The effect of psychological interventions on anxiety and depression in cancer patients: results of two meta-analyses. British Journal of Cancer, $80,1770-1780$.

Simning, A., Conwell, Y., Mohile, S. G., \& van Wijngaarden, E. (2014). The moderating effect of age on the 12-month prevalence of anxiety and depressive disorders in adults with a lifetime history of cancer. The American Journal of Geriatric Psychiatry, 22, 1399-1409.

Spek, V., Cuijpers, P., Nyklicek, I., Riper, H., Keyzer, J., \& Pop, V. (2007). Internet-based cognitive behaviour therapy for symptoms of depression and anxiety: a meta-analysis. Psychological Medicine, 37, 319-328.

Steel, J. L., Geller, D. A., Kim, K. H., Butterfield, L. H., Spring, M., Grady, J., ... Tsung, A. (2016). Web-based collaborative care intervention to manage cancer-related symptoms in the palliative care setting. Cancer, 122, 1270-1282.

Stefanopoulou, E., Yousaf, O., Grunfeld, B., \& Hunter, M. (2015). A randomised controlled trial of a brief cognitive behavioural intervention for men who have hot flushes following prostate cancer treatment (MANCAN). Psycho-Oncology, 24, 1159-1166.

Stewart, L., \& Tierney, J. (2002). To IPD or not to IPD? Advantages and disadvantages of systematic reviews using individual patient data. Evaluation \& the Health Professions, 25, 76-97.

Stoerkel, E., Bellanti, D., Paat, C., Peacock, K., Aden, J., Setlik, R., ... Inman, A. (2018). Effectiveness of a self-care toolkit for surgical breast cancer patients in a military treatment facility. Journal of Alternative and Complementary Medicine, 24, 916-925.

Strong, V., Waters, R., Hibberd, C., Murray, G., Wall, L., Walker, J., ... Sharpe, M. (2008). Management of depression for people with cancer (SMaRT oncology 1): a randomised trial. The Lancet Oncology, 372, 40-48.

Tierney, J., Vale, C., Riley, R., Smith, C., Stewart, L., Clarke, M., \& Rovers, M. (2015) Individual Participant Data (IPD) meta-analyses of randomised controlled trials: guidance on their use. PLOS Medicine, 12.

Van der Meulen, I. C., May, A. M., Ros, W., Oosterom, M., Hordijk, G.-J., Koole, R., \& de Leeuw, J. R. J. (2012). One-year effect of a nurse-led psychosocial intervention on depressive symptoms in patients with head and neck cancer: a randomized controlled trial. The Oncologist, 18, 336-344.

van de Wal, M., Thewes, B., Gielissen, M. F. M., Speckens, A., \& Prins, J. B. (2017). Efficacy of blended cognitive behavior therapy for high fear of recurrence in breast, prostate, and colorectal cancer survivors: The SWORD study, a randomized controlled trial. Journal of Clinical Oncology, 36.

Wells-Di Gregorio, S. M., Marks, D. R., DeCola, J., Peng, J., Probst, D., Zaleta, A., . Magalang, U. (2019). Pilot randomized controlled trial of a symptom cluster intervention in advanced cancer. Psychooncology, 28, 76-84.

Willems, R. A., Mesters, I., Lechner, L., Kanera, I. M., \& Bolman, C. A. W. (2017). Long term effectiveness and moderators of a web-based tailored intervention for cance survivors on social and emotional functioning, depression, and fatigue: randomized controlled trial. Journal of Cancer Survivorship, 11, 691-703.

Williams, S., \& Dale, J. (2006). The effectiveness of treatment for depression/depressive symptoms in adults with cancer: a systematic review. British Journal of Cancer, 94 372-390.

Wu, H., Zhong, H., Xu, Y., Xu, C., Zhang, Y., \& Zhang, W. (2016). Psychological and behavioral intervention improves the quality of life and mental health of patients suffering from differentiated thyroid cancer treated with postoperative radioactive iodine-131. Neuropsychiatric Disease and Treatment, 12.

Yang, H., Brand, J. S., Fang, F., Chiesa, F., Johansson, A. L. V., Hall, P., \& Czene, K. (2016). Time-dependent risk of depression, anxiety, and stress-related disorders in patients with invasive and in situ breast cancer. International Journal of Cancer, 140, 841-852.

Zhu, L., Ranchor, A., van der Lee, M., Garssen, B., Almansa, J., Sanderman, R., \& Schrovers, M. (2017). Co-morbidity of depression, anxiety and fatigue in cancer patients receiving psychological care. Psycho-Oncology, 26, 444-451. 